\title{
Multi-Scale Modelling of Flexible End Plate Connections under Fire Conditions
}

\author{
Ying Hu*, Buick Davison, Ian Burgess and Roger Plank
}

Department of Civil and Structural Engineering, The University of Sheffield, Sheffield S1 3JD, UK; School of Architecture, The University of Sheffield, Sheffield S10 2TN, UK

School of Architecture, The University of Sheffield, Sheffield S10 2TN, UK

\begin{abstract}
Conducting experimental tests is an attractive and straight-forward research approach but is time-consuming and expensive in comparison with finite element modelling. A numerical approach has been developed in this project to investigate the performance of simple steel connections in fire conditions. This paper presents a quasi-static numerical analysis with cohesive elements to investigate the resistance and ductility (rotation capacity) of simple steel connections (flexible end plates) in fire conditions. In comparison with experimental test data, a good correlation with the finite element analysis is achieved and the method is suitable to study the tying resistance and ductility for simple steel connections with various dimensions at different temperatures.

This numerical approach was also compared with component-based connection models, which have been developed in the previous research work. The analytical results produced demonstrated that the component-based approach is capable of as an alternative method to analyse the connection performance under fire and non-fire conditions, and this approach is simple but without loss of accuracy.
\end{abstract}

Keywords: Flexible end-plate connections, finite element modelling, explicit, structural fire engineering, fire.

\section{INTRODUCTION}

Conducting fire tests on structures or isolated structural members is time-consuming, expensive, and poses the additional difficulties of recording movement and strain within a furnace. So the development of accurate predictive methods to simulate the behaviour of steel structures in fire has long been regarded as desirable [1]. The ABAQUS program has been used to study the behaviour of steel and composite framed structures in fire by Corus Research [2, 3] and Edinburgh University [4, 5]. This finite element programme shows the ability to simulate complex structural behaviour under fire conditions as comparisons with test results from the Cardington fire tests demonstrated. This commercial programme has a large library of finite elements to enable efficient and detailed modelling of many of the special features of structural behaviour in fire. The complex real phenomena such as local/distortional buckling, lateral torsional buckling, detailed connection modelling and membrane actions can be accounted for in a numerical fashion. Therefore, detailed finite element modelling of connections in fire provides a good opportunity for wider parametric investigations and eliminates the limitations associated with experiments [6], provided that the numerical models have been adequately validated against experimental data.

Initial attempts to simulate steel connections started with two dimensional models, owing to the limitations in compu

*Address correspondence to this author at the Department of Civil and Structural Engineering, The University of Sheffield, Sheffield S1 3JD, UK; Tel: 011422 25763; Fax: 011427 98276;

E-mail: cip05yh@sheffield.ac.uk tational resources both in terms of software and hardware. In a $2 \mathrm{D}$ model, each component of a connection can be represented by using shell or truss elements, and the interactions between these components are numerically simplified to avoid convergence difficulties in the numerical computation. Because of the rapid improvement in hardware and software, computers are now able to perform more detailed simulations for connections in 3D models. Krishnamurthy et al. [7] and Kukreti et al. [8] compared numerical results produced by two-dimensional and three-dimensional simulations, and found the three-dimensional numerical model to be more flexible than the two-dimensional counterpart, resulting in larger displacements and stresses. Vegte et al. [9] believe that, since bolted steel connections are three-dimensional in nature, two-dimensional numerical models are therefore unable to represent the three-dimensional behaviour satisfactorily. Hence, a three-dimensional non-linear finite element analysis approach has been developed as an alternative method for the investigation of connection robustness in fire.

\section{THE FINITE ELEMENT MODEL DESCRIPTION}

Sherbourne and Bahaari $[10,11]$ developed a threedimensional finite element model for simulating endplate connections by using brick elements. The model was assumed to have a continuous connection between the nodes of the bolt head and nut, and the nodes of end plates, and as a consequence, the relative motions between bolt, column flange and end plates were numerically simplified. The bolt shank behaviour was represented using truss elements instead of brick elements which prevents the numerical model reproducing properly the bearing action between bolts and bolt holes, because the interface between the bolt shank and 
the hole boundary was neglected. Bursi and Jaspart [12] presented a more realistic finite element model for T-stub connections. This numerical model is capable of simulating the complex interactions such as contact, friction, stick and slip conditions, stress concentrations and prying actions in a real connection. Bolts and endplates in the simulation are represented as individual components using brick elements, and are no longer connected through common nodes, enabling relative movement between these components [13]. Although this numerical approach results in finite element simulations which are much more complicated and computationally expensive in terms of time, it has nevertheless been adopted by many researchers owing to the improvement in numerical accuracy.

A three dimensional numerical model was created for a flexible end plate connection, using the ABAQUS finite element code, in order to investigate its resistance and ductility at ambient and elevated temperatures. This model started with the creation of individual components such as bolts, endplates, beams and columns, and then assembled these components into a connection, as shown in Fig. (1).

All these components were modelled using eight-node continuum hexahedral brick elements. A small number of cohesive elements were used in the heat affected zone (HAZ) where the failure of endplates was seen to occur. The brick element has the capability of representing large deformation, and geometric and material nonlinearity, whilst the traction separation law of cohesive elements is able to demonstrate the rupture of end plates in a real connection. The contacts between bolts, endplates and column flanges were simulated by surface-to-surface formulations. In order to simulate this nonlinear performance, an intensive mapped mesh was made within the bolts and the vicinity of the bolt holes, shown in Fig. (1). The following discusses the details of how to create a FE model for a flexible end plate connection.

\subsection{Solution Strategies in Solving Nonlinearity}

In most nonlinear problems, there are three sources of nonlinearity in structural mechanics simulations: material nonlinearity, boundary nonlinearity and geometric nonlinearity [14]. Material nonlinearity is commonly observable in most metals and rubber materials. For example, steel has a fairly linear stress/strain relationship at low strain values; but at higher strains such a relationship becomes highly nonlinear due to material yielding, at which point the response becomes irreversible. Boundary nonlinearity takes place if the boundary conditions change during the analysis. Consider the cantilever beam shown in Fig. (2) as an example, the vertical displacement of the beam tip is linearly related to the applied load before the beam tip contacts the stop. The third source of nonlinearity is related to changes in the geometry of the numerical model resulting in a dramatic change in the stiffness of this model during the analysis. This may be caused by large deflections/rotations, snap through and initial stresses/load stiffening. These nonlinear problems can be treated within ABAQUS in two different solution strategies: Standard Analysis and Explicit Solution.

The Standard Analysis in ABAQUS is implicitly based on static equilibrium (internal forces $\boldsymbol{I}$ and external forces $\boldsymbol{P}$ must balance each other), characterized by an assembly of a global stiffness matrix and the simultaneous solution of a set

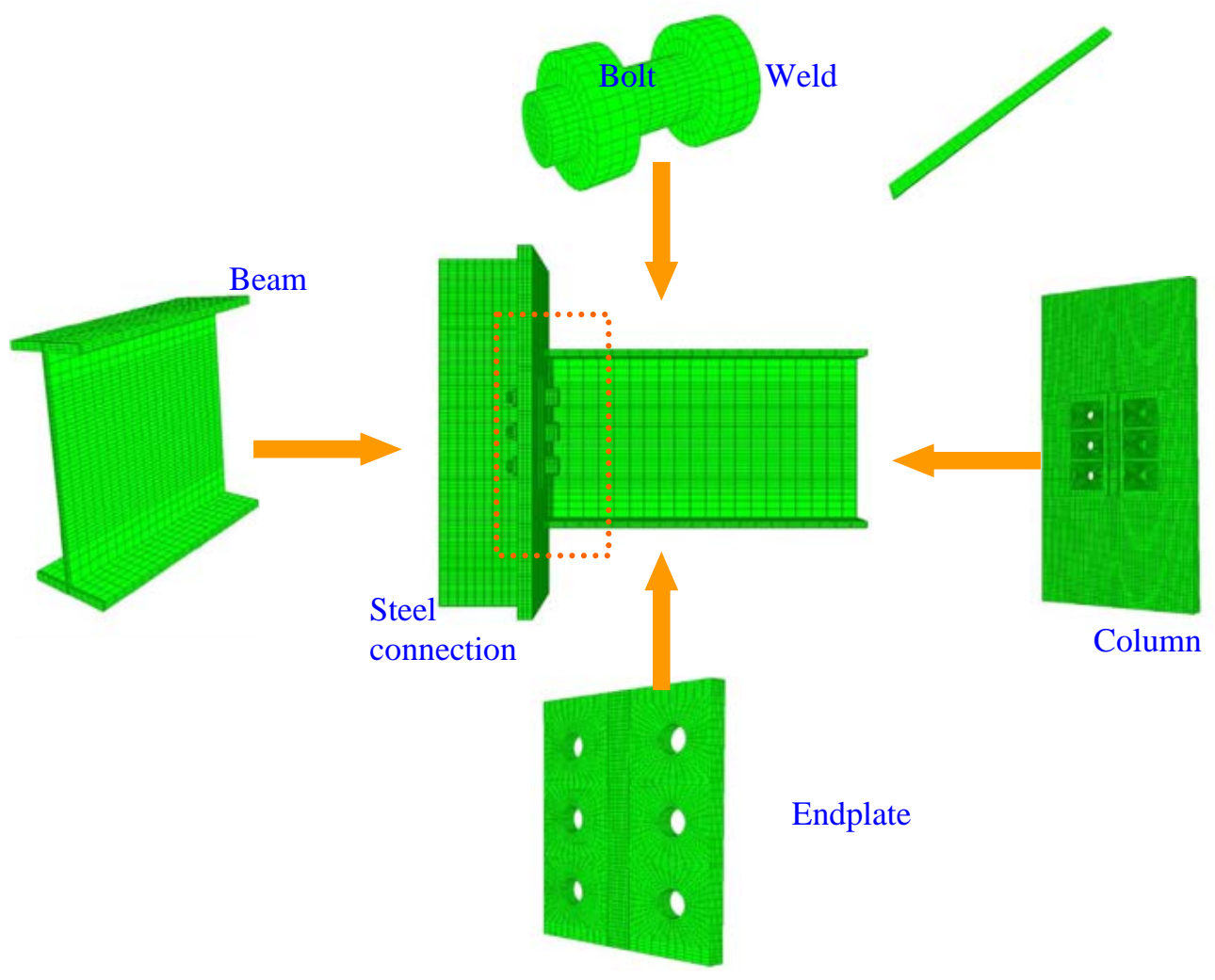

Fig. (1). Components to be assembled to form a FE model for a flexible end plate connection. 


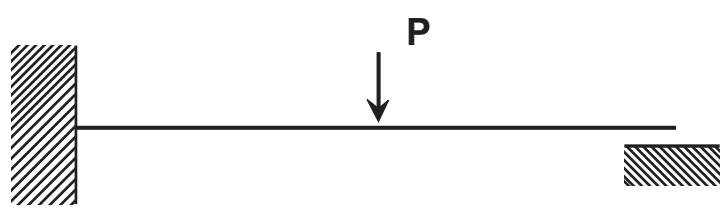

Fig. (2). Cantilever beam hitting a stop [14].

of linear or nonlinear equations [13]. The Newton-Raphson method is used to converge the solution at each time step along the force deflection curve. By default, this method adjusts the size of the time increments automatically during the analysis (automatic incrementation control), and only the size of the first increment in each step needs to be specified for solving nonlinear problems. This default function is suitable for most nonlinear static analyses. However, the nonlinear static problems can be unstable, i.e. the tangent stiffness of a numerical model is close to zero or negative during the analysis. Such instabilities may be caused by local/global buckling or material softening under fire conditions. If the tangent stiffness is zero or negative the classical NewtonRaphson method is unable to achieve the convergence, so the standard analysis presents an automatic stabilization mechanism for unstable quasi-static problems through automatic addition of volume-proportional damping to the numerical model. The damping factors applied can be constant within a step or can vary over the course of a step, which is typically preferred for the adaptive approach. In addition, to avoid these unstable problems, the Riks method (Arc-Length algorithm) can be used to allow the load and displacement to vary throughout the time step [14]. Nevertheless, for a numerical model with complicated contact interactions, these two solution algorithms are unlikely to produce an easy and smooth solution in the computation.

For complex contact problems and highly nonlinear quasi-static problems, the Explicit Solution is very efficient in solving certain classes of unstable static analyses. The Explicit Solution approach is a dynamic-based numerical procedure, originally developed to simulate high-speed impact events in which inertia plays a dominant role in the analysis. Achieving convergence is not needed in the simulation. This approach has proven to be valuable in dealing with unstable static problems and is much easier to use for resolving complicated contact problems in comparison with the Standard Analysis. In addition, for a very large numerical model, the explicit procedure requires less system resources than the implicit procedure [14]. However, to achieve a realistic simulation for a static problem, the minimum stable time increment is usually quite small and hence most problems require a large number of increments.

Since a quasi-static event needs a long-time process, it is often computationally impractical to have the simulation in its natural time scale, which would require an excessive number of small time increments [14]. Therefore, some special considerations need to be taken in applying the explicit dynamic procedure to solve quasi-static problems. To achieve an economical solution, such an event must be accelerated in some way in the simulation; however, the arising problem is that inertial forces (dynamic effects) become more dominant as the event is accelerated and the issue of static equilibrium evolves into an issue of dynamic equilibrium. So the crucial point for a quasi-static simulation is to model the event in the shortest time period in which inertial forces remain insignificant. In order to achieve this, Vegte [13] recommends researchers to monitor the various components of the energy balance throughout the loading process. The total energy in the system $\left(\boldsymbol{E}_{\text {total }}\right)$ remains constant during the explicit solution procedure. If a simulation is quasistatic, the work applied by the external forces $\left(\boldsymbol{E}_{W}\right)$ is nearly equal to the internal energy of the system $\left(\boldsymbol{E}_{\boldsymbol{I}}\right)$, as shown in Fig. (3). The viscously dissipated energy is generally small and the inertial forces are negligible in a quasi-static analysis due to the small velocity of the material in the model. As a general rule, the kinetic energy $\left(\boldsymbol{E}_{\boldsymbol{K} E}\right)$ of the deforming material should not exceed a small fraction (typically $5 \%$ to $10 \%$ ) of its internal energy throughout most of the process [14]. In order to reduce the solution time in simulations, mass scaling (artificially increasing the mass to reduce inertial effects) is an alternative option to researchers, which enables an analysis to be performed economically without increasing the loading rate [14]. This option is also used to deal with simulations involving a rate-dependent material or rate-dependent damping. In these simulations, increasing loading rate is not allowed in the analysis because material strain rate increases by the same factor as the loading rate. Therefore, mass scaling is the only option to achieve a quasi-static solution.

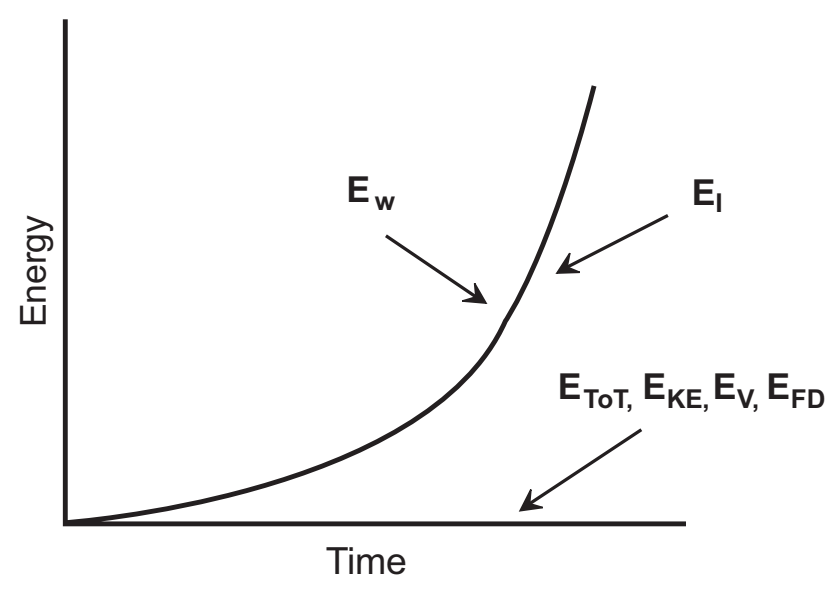

Fig. (3). Energy balance in a quasi-static analysis [14].

For the Explicit Solution, the crucial consideration is the stability limit, which determines the maximum time increment used in a quasi-static analysis. The stability limit has a great effect on reliability and accuracy during the analysis. If the time increment is larger than this maximum amount of time, the increment is said to have exceeded the stability limit. A possible side effect of exceeding this limit is numerical instability, which may lead to a diverged solution. For computational efficiency, the explicit approach adopts time increments as close as possible to the stability limit without exceeding it. Furthermore, a simple and efficient estimate can be made for determining the stability limit, based on formulation (1) and (2), although it is not computationally feasible to calculate the exact value of the stability limit in a system [14]. 


$$
\Delta t_{\text {stable }}=\frac{L^{e}}{c_{d}}
$$

Where $L^{e}$ is the element length and $c_{d}$ is the wave speed of the material, which can be determined by:

$$
c_{d}=\sqrt{\frac{E}{\rho}}
$$

Where $E$ is the Young's modulus and $\rho$ is the mass density. The stiffer the material, the higher the wave speed, resulting in a smaller stability limit; the higher the density, the lower the wave speed, resulting in a larger stability limit. For more details of the stability limit, readers are referred to the Abaqus Help Documentation 6.7 [14], which explains an analytical approach for the calculation of the exact stability limit, based on the highest frequency and critical damping in a system.

\subsection{Element Types}

ABAQUS contains a large variety of hexahedron (brick), shell, contact and beam elements endowed with different features depending on the application. Kukreti et al. [8] and Gebbeken et al. [15] carried out a comparative investigation on numerical techniques in analyzing bolted steel connections with the intention of reproducing the experimental results in a finite element fashion. They set up a twodimensional finite element model (using shell elements) and a three-dimensional finite element model (using brick elements) within ABAQUS. The comparison between numerical results and experimental data illustrated that the twodimensional model was too stiff for the representation of the real deformations [15], and the hexahedron (brick) element was much more suitable to model the continuum behaviour of bolted connections compared to standard shell elements.

The current ABAQUS element library offers engineers and numerical analysts a number of hexahedron elements in finite element simulations. For hyperbolic problems (plasticity-type problems), Bursi and Jaspart [16] suggest that the first order elements are likely to be the most successful in reproducing yield lines and strain field discontinuity. This is because some components of the displacement solution can be discontinuous at element edges. Simulations performed by Bursi and Jaspart [16] compared three eight-node brick elements: (1) The C3D8 element with full integration (8 Gauss points). This element is accurate in the constitutive law integration but the shear locking phenomenon is commonly associated with it when simulating bendingdominated structures [14]. (2) The C3D8R element with reduced integration (1 Gauss point). This element supplies a remedy for the shear locking problem caused by using C3D8, but the rank-deficiency of the stiffness matrix may produce spurious singular (hourglassing) modes [14], which can often make the elements unusable. In order to control the hourglass modes in elements, Flanagan and Belytschko [17] proposed the artificial stiffness method and the artificial damping method in the ABAQUS code; although the artificial damping approach is available only for the solid and membrane elements in ABAQUS Explicit. (3) The C3D8I element with full integration (8 Gauss points) and incom- patible modes. This element has 13 additional degrees of freedom and the primary effect of these degrees of freedom is to eliminate the so-called parasitic shear stresses that are observed in regular displacement elements in analyzing bending-dominated problems [14]. In addition, these degrees of freedom are also able to eliminate artificial stiffening due to Poisson's effect in bending.

Through comparative modelling with the aforementioned three brick elements, the C3D8I elements were found to perform particularly well both in the elastic and inelastic regimes, and are suitable for representing the bendingdominated behaviour of a structure [12]. As expected from the theoretical formulation, C3D8R elements underestimate the strength value and the plastic failure load in the finite element modelling. From calibration tests, Bursi and Jaspart [12] also state that C3D8 elements appear to be unsatisfactory, owing to the overestimation of the plastic failure load and the shear locking phenomenon. Therefore, in order to predict the behaviour in a conservative fashion, the element selected for bolted steel connections is the reduced integration brick element C3D8R. In order to control the hourglass modes, a very dense mesh finite element model has been set up.

\subsection{Contact Modelling Within ABAQUS}

In numerical simulations, obtaining realistic representation of connection performance depends upon handling the difficult issues of modelling the contact interaction between various joint components. Within ABAQUS, the contact behaviour can be simply reproduced by using so-called "gap elements", which require the user to define pairs of nodes and specify the value of a clearance gap. These elements allow for two nodes to be in contact (gap closed) or separated (gap open) under large displacements [12]. The limitation of this sort of element is the friction between two contacted components being ignored in the simulation. Furthermore, simulation using these elements is a tedious and timeconsuming task [13].

In order to overcome these problems, a "surface-tosurface" contact interaction was developed for the numerical model. The simulation requires the researcher to first determine the slave and master surfaces for two deformable bodies and then define the interaction behaviour between these two surfaces. In the standard analysis, ABAQUS affords two formulations, small-sliding formulation and finite-sliding formulation, for modelling the interaction between two discrete deformable bodies. In the explicit analysis, the interactions between surfaces are modelled by a different contact formulation, which includes the constraint enforcement method, the contact surface weighting, the tracking approach and the sliding formulation. In the explicit analysis, the friction conditions (sliding and sticking) between the master and slave surfaces may be represented by the classical isotropic Coulomb friction model, which has proved to be suitable for steel elements [18]. However, it is of great importance to be careful with the assignment of the slave and master surfaces [6]. It is generally accepted that the surfaces working as master surfaces should belong to the bodies with the stronger material or a finer mesh. So the contact surfaces of the bolt shank, bolt head and bolt nut are always modelled as master surfaces in this research, as highlighted in red in Fig. (4). In 


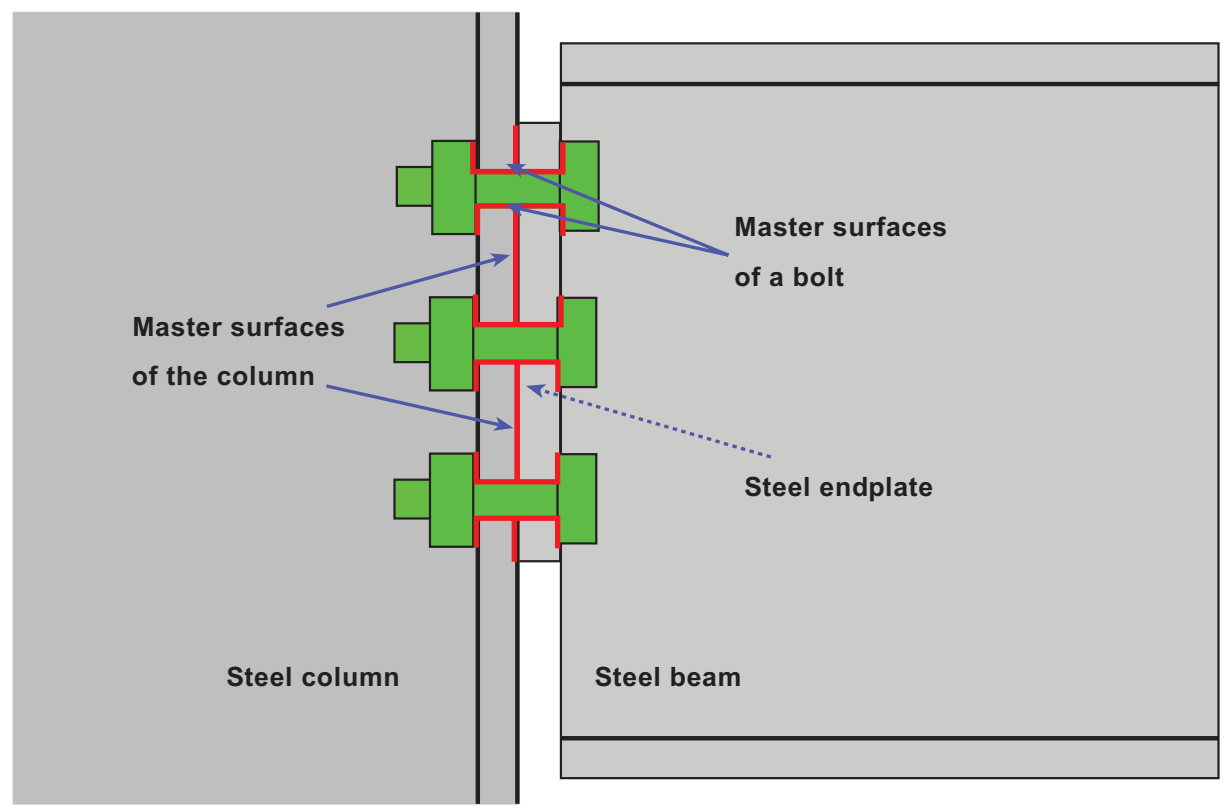

Fig. (4). Master surfaces for a finite element connection model.

the contact action between the column and the endplate, the column face is always the master surface in the numerical model because these columns are likely to be of a higher grade steel (S355) compared with the plates which are most often S275. In simulating bolted steel connections, experience shows that heat generation caused by frictional sliding is not significant in experimental tests and therefore may be ignored in the finite element modelling. A friction coefficient $\mu$ of 0.25 has been accepted for all contact surfaces during the analysis and pretension was not applied to the bolts, in line with structural steelwork construction practice.

\subsection{Mesh Convergence}

As far as the stability limit is concerned, it is advantageous to keep the element size as large as possible during the analysis. However, coarse meshes in a model can produce inaccurate numerical results. Moreover, the numerical solution for a model is required to create a unique value as the mesh density increases during the solution procedure [14]. So the mesh of a numerical model is said to be converged, when further mesh refinement yields a negligible change in the analysis. For the brick elements, Sarraj [6] created a number of finite element models with different mesh sizes for a mesh convergence check. The deflections and stresses of these models were plotted against the number of mesh elements. The numerical results show the deflections and stresses started to converge in a numerical model with approximately 1500 elements. So the mesh pattern used in his research has been adopted in the finite element analyses in the current research work.

\subsection{Material Properties for a Finite Element Model}

For realistic simulations, Bursi and Jaspart [16] note that proper material properties are required to be adopted in the solution procedure. The material properties for the various components of steel connections may be determined from the engineering stress-strain relationship using nonlinear material curves recommended in Eurocode 3. They may also be defined according to stress-strain relationships obtained in standard tensile tests of steel. However, the stress-strain relationships determined by these two approaches are very different in the plastic region, as shown in Fig. (5) (the dashed blue curve indicates the Eurocodes-based stress-strain relationship and the solid red curve presents the relationship of stresses and strains produced in the steel tensile tests). This is because Eurocode 3 stresses are intended to give a safe margin for design purposes rather than simulation. As a result of this, the stress-strain relationships based on experimental results have been applied to the numerical model throughout this study.

In these connection tests, a 254UC89 was used for the column and a $305 \times 165 \mathrm{UB} 40$ for the beam. The thickness of the end plate was $10 \mathrm{~mm}$. The steel used was S275 for endplates and UB sections; and S355 was used for UC sections. All the bolts were M20 grade 8.8 used in $2 \mathrm{~mm}$ clearance holes. The nominal material properties of these structural components are summarised in Table $\mathbf{1}$.

The stress-strain relationships for the structural steel and 8.8 bolts are illustrated in Fig. (6), and are the same as those used by Sarraj [6].

Since the ABAQUS codes operate in a large deformation setting, in order to consider the deformed area the nonlinear relationship of true stress versus true strain is required to be defined for steel components. However, most material test data are supplied with engineering stresses and strains (nominal stresses and nominal strains) according to the uniaxial material testing response [19]. In such situations, it is necessary to convert material data from engineering stress and strain to true stress and strain using the following relationship:

$\sigma_{\text {true }}=\sigma_{\text {nom }}\left(1+\varepsilon_{\text {nom }}\right)$

$\sigma_{\text {true }}$ is the true stress 


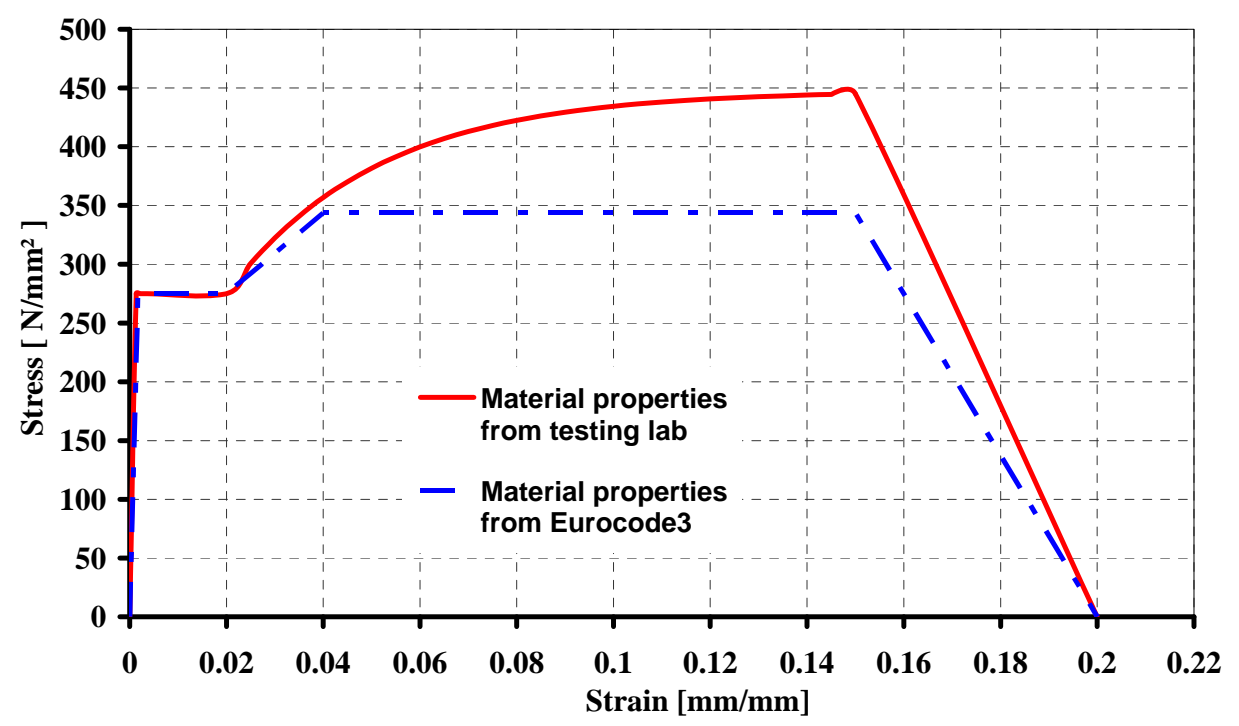

Fig. (5). Material properties for steel.

Table 1. Material Properties of Steel and Bolt Steel

\begin{tabular}{|c|c|c|c|c|c|}
\hline Material Type & $\begin{array}{c}\text { Yield Stress } \\
{\left[\mathbf{N} / \mathbf{m m}^{2}\right]}\end{array}$ & $\begin{array}{c}\text { Ultimate Stress } \\
{\left[\mathbf{N} / \mathbf{m m}^{2}\right]}\end{array}$ & $\begin{array}{c}\text { Density } \\
{\left[\mathbf{k g} / \mathbf{m}^{3}\right]}\end{array}$ & $\begin{array}{c}\text { Young's Modulus } \\
{\left[\mathbf{k N} / \mathbf{m m}^{2}\right]}\end{array}$ & 205 \\
\hline \hline S275 & 275 & 450 & 7850 & 205 & 0.3 \\
\hline S355 & 355 & 550 & 7850 & 205 & 0.3 \\
\hline 8.8 bolt & 640 & 800 & 7850 & 0.3 \\
\hline
\end{tabular}

$\sigma_{\text {nom }}$ is the nominal stress

$\varepsilon_{\text {nom }}$ is the nominal strain

The relationship between the true strain and nominal strain is defined as:

$\varepsilon_{\text {true }}=\ln \left(1+\varepsilon_{\text {nom }}\right)$

The true stress $\left(\sigma_{\text {true }}\right)$ is a function of the nominal stress and nominal strain; and the true strain (true total strain, $\varepsilon_{\text {true }}$ ) is determined by the logarithm of nominal strain (total strain, $\left.\varepsilon_{\text {nom }}\right)$. For inputting into ABAQUS, the total strain values ( $\varepsilon$ true) should be decomposed into the elastic and plastic strain components $\left(\varepsilon_{\mathrm{el}, \text { true }}\right.$ and $\left.\varepsilon_{\mathrm{pl} \text {, true }}\right)$. The true elastic strain $\left(\varepsilon_{\mathrm{el}}\right.$, true) can be captured by the true stress $\left(\sigma_{\text {true }}\right)$ divided by the Young's modulus (E); and the true plastic strain, required for the explicit solution procedure, can be obtained using the following relationship:

$\varepsilon_{\mathrm{pl}, \text { true }}=\varepsilon_{\text {true }}-\varepsilon_{\mathrm{el}, \text { true }}=\ln \left(1+\varepsilon_{\text {nom }}\right)-\sigma_{\text {true }} / \mathrm{E}$

Once we have the stress-strain relationships of steel components at the ambient temperatures, the relationships of stresses and strains at high temperatures can be produced based on the reduction factors for the strength and Young's modulus, which has already been documented in the European standard.

\subsection{Modelling Rupture with Cohesive Elements}

To simulate the rupture process of a connection, the classical failure criterion adopted is to assume that the steel ma- terial starts softening at $15 \%$ strain and the strength drops to zero at $20 \%$ strain. But the performance of fillet welds and the material around these welds appear to be very brittle in the experimental tests. So Kanvinde et al. [20] carried out some detailed research on fillet welds. Fracture of fillet welds in connections has been found to be a typical failure mechanism and the fracture displacements of these fillet welds are commonly in the range of $0.71 \mathrm{~mm}$ and $1.93 \mathrm{~mm}$. Moreover, the experimental results in the paper of $\mathrm{Hu}$ et al. [21] showed that the rupture of endplates always took place around the heat affected zone (HAZ) in a partial depth endplate connection. So a small number of cohesive elements have been embedded into the heat affected zone in the numerical model to capture this failure behaviour. Cohesive elements represent a fracture of a material as a separation across a surface and the constitutive response of these elements is determined by the relationship of traction versus separation (traction separation law), as shown in Fig. (7). When these cohesive elements and their neighbouring components have matched meshes, it is straightforward to connect cohesive elements to other elements in a model simply by sharing nodes. If the neighbouring elements do not have matched meshes, ABAQUS enables the cohesive elements to be connected to other components by using surface-based tie constraints [14].

The available traction-separation model in ABAQUS assumes initially linear elastic behaviour followed by the initiation and evolution of damage. To determine this constitu- 


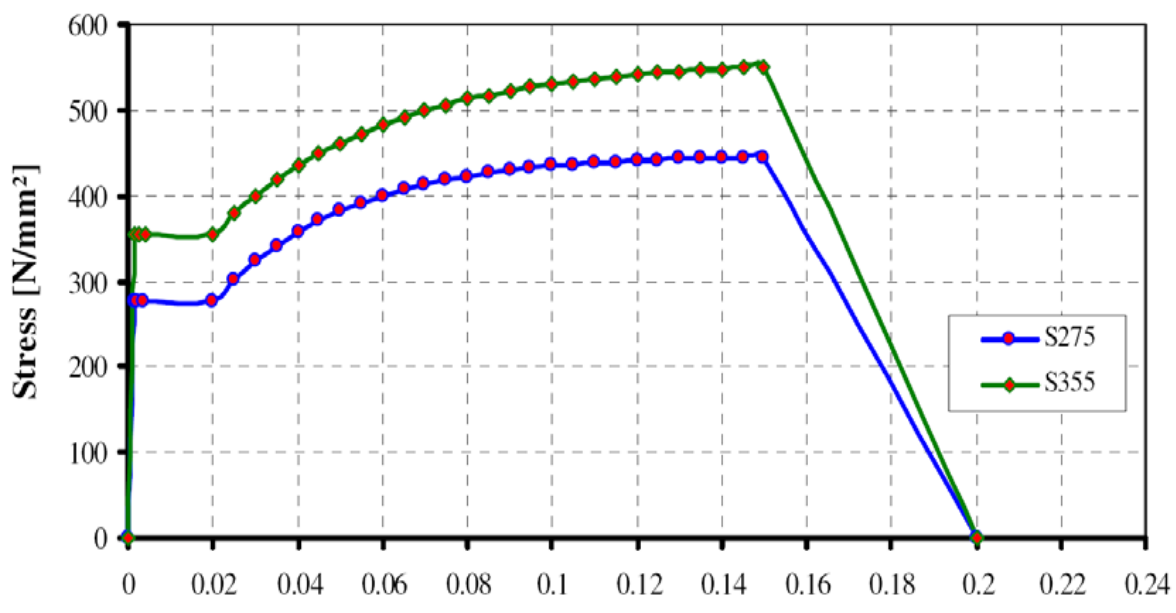

Strain $[\mathrm{mm} / \mathrm{mm}]$

(a)

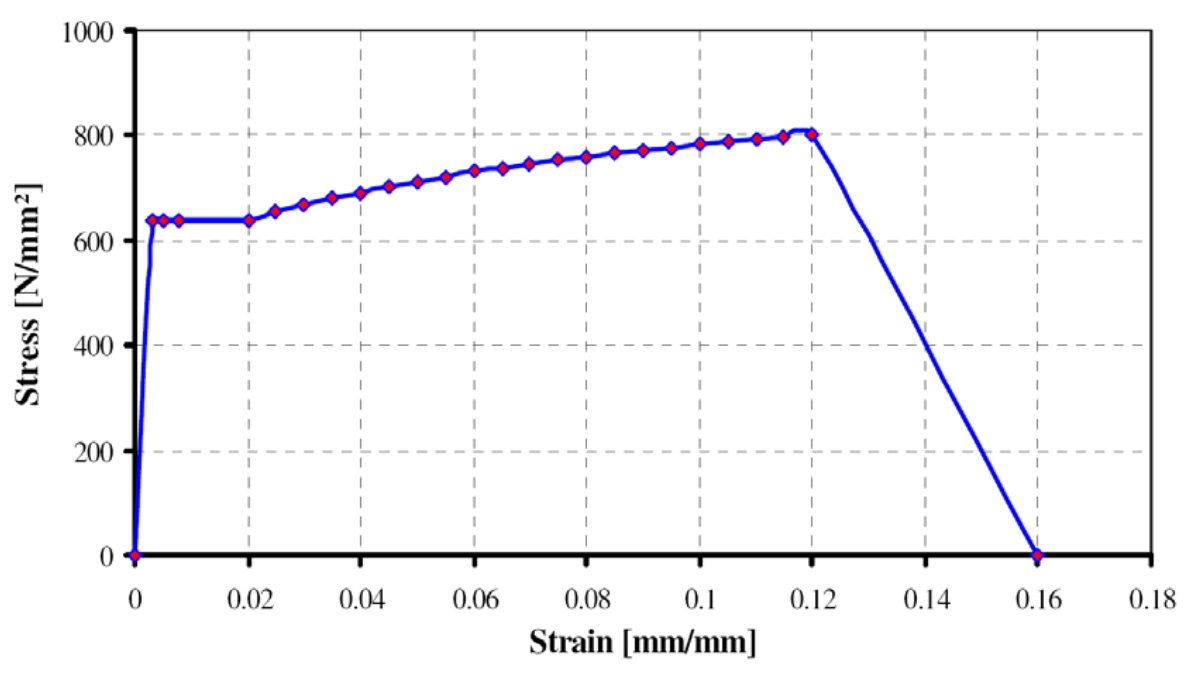

(b)

Fig. (6). Stress-strain curves for (a) S275 and S355 steel and (b) grade 8.8 high strength bolts [6].

tive response, a number of parameters, such as critical separation $\left(\delta_{0}\right)$, cohesive energy $\left(\Gamma_{o}\right)$ and cohesive strength $\left(T_{0}\right)$, are required for the explicit solution procedure, as displayed in Fig. (7). Cornec et al. [22] recommend that the cohesive strength $\left(T_{0}\right)$ may be taken as the maximum stress at fracture in a round notched tensile bar. But Scheider et al. [23] add that this procedure might not be applicable to thin specimens, as round notched bars can not be machined from sheet metal and the individual failure mode (normal fracture) would be different from that in the flat specimen (slant fracture). As an estimation for the simulation, Scheider et al. [23] recommend that the nominal stress of the flat tensile specimen at fracture (load divided by the area of the normal projection of its inclined fracture surface, $\mathrm{F}_{\text {frac }} / \mathrm{A}_{\text {frac }} \approx 470.5$ Mpa) may be used as $T_{0}$. To simulate the progressive damage in the cohesive zone, it is of great importance to determine the critical separation $\left(\delta_{0}\right)$ and cohesive energy $\left(\Gamma_{0}\right)$. The determination of $\delta_{0}$ heavily relies on experience in nu- merical simulation and experimental tests, and three times the separation value at damage initiation $\left(\delta_{l}\right.$, shown in Fig. (7)) or over has been adopted for the explicit solution procedure. Thus the cohesive energy $\left(\Gamma_{0}\right)$ may be estimated by using one of the following relationships [22]:

$\Gamma_{o}=0.87 T_{0} \delta_{0}$

or

$\Gamma_{o}=T_{0} \delta_{0}$

\section{COMPARISON OF NUMERICAL RESULTS WITH EXPERIMENTAL TESTS}

It is a standard procedure for numerical models to be validated against experimental results at ambient temperatures and also at elevated temperatures. The experimental data was taken from connection test results carried out at the University of Sheffield [21, 24-26]. 


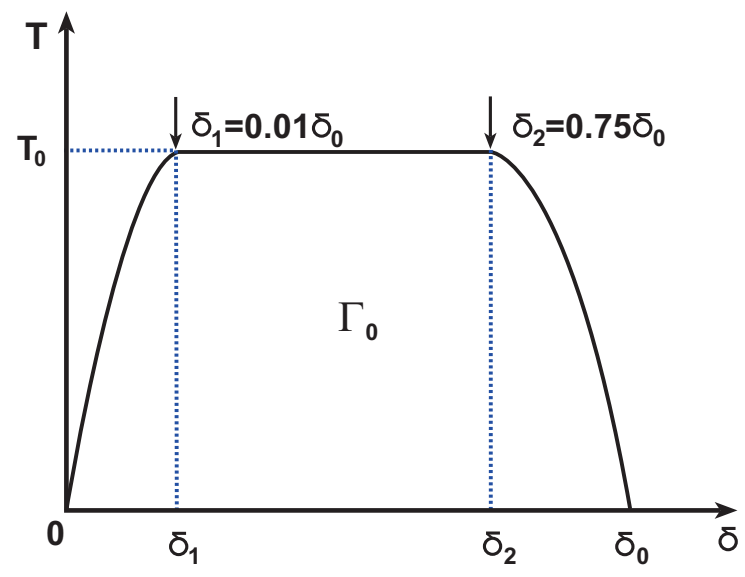

Fig. (7). Traction-separation law for fracture [22].

\subsection{Comparison of Flexible End Plate Model at Ambient Temperatures}

The author investigated the resistance and rotation capacity (ductility) of one typical simple connection type (partial depth endplate) subjected to inclined tying forces at both ambient and elevated temperatures [21]. In this programme, twelve connection tests have been performed for end plate connections, including three tests at ambient temperatures and nine tests for high temperatures. The loading angles $\left(35^{\circ}, 45^{\circ}, 55^{\circ}\right)$ of applied forces for these tests have been determined initially, which are also shown in Figs. $(\mathbf{1 0}, \mathbf{1 1})$ and (12) for illustration. The deformation (rotation) in the connection zone was recorded by inclinometers (angular transducers) for the first three tests at ambient temperatures, and the applied external force was captured by strain gauges on the loading system.

The numerical model was developed for flexible end plates using the ABAQUS commercial software package (as outlined in section 2), and the geometrical details of the numerical model are shown in Fig. (8) and material properties used in Table 1. Dimensions in Fig. (8) are shown in $\mathrm{mm}$ used for this series of studies. The rotation of a connection FE model has been recorded through monitoring horizontal and vertical displacements of two target nodes in the loading process.

The deformed and undeformed shapes of the numerical model are displayed for flexible end plates in Fig. (9), including the contour plots for the components as well, such as bolts and endplates. The FE analysis clearly demonstrates that the rotation capacity of these connections is mainly produced by deformation in the end plates, welds and bolts, and the deformation of the column flange and beam web may be neglected in the analysis. The ductile failure mechanism of partial depth endplates has been represented in the simulation.

For simple steel connections, the relationships of moments and rotations are not of great importance in the sense of structural design (they are assumed to be pinned). Of greater concern is the response of these connections to the inclined tying forces and their ductility under fire conditions. So the relationships of loads and rotations of the numerical model have been compared with experimental data of three connection tests at ambient temperatures, as shown in Fig. (10). The red curves in Fig. (10) (a), (b) and (c) are the numerical plots produced in ABAQUS; and the loads and rotations recorded in the experimental tests are displayed in green. The kink in the green curve is at about $6^{\circ}$ rotation and corresponds to the point where the beam bottom flange con-

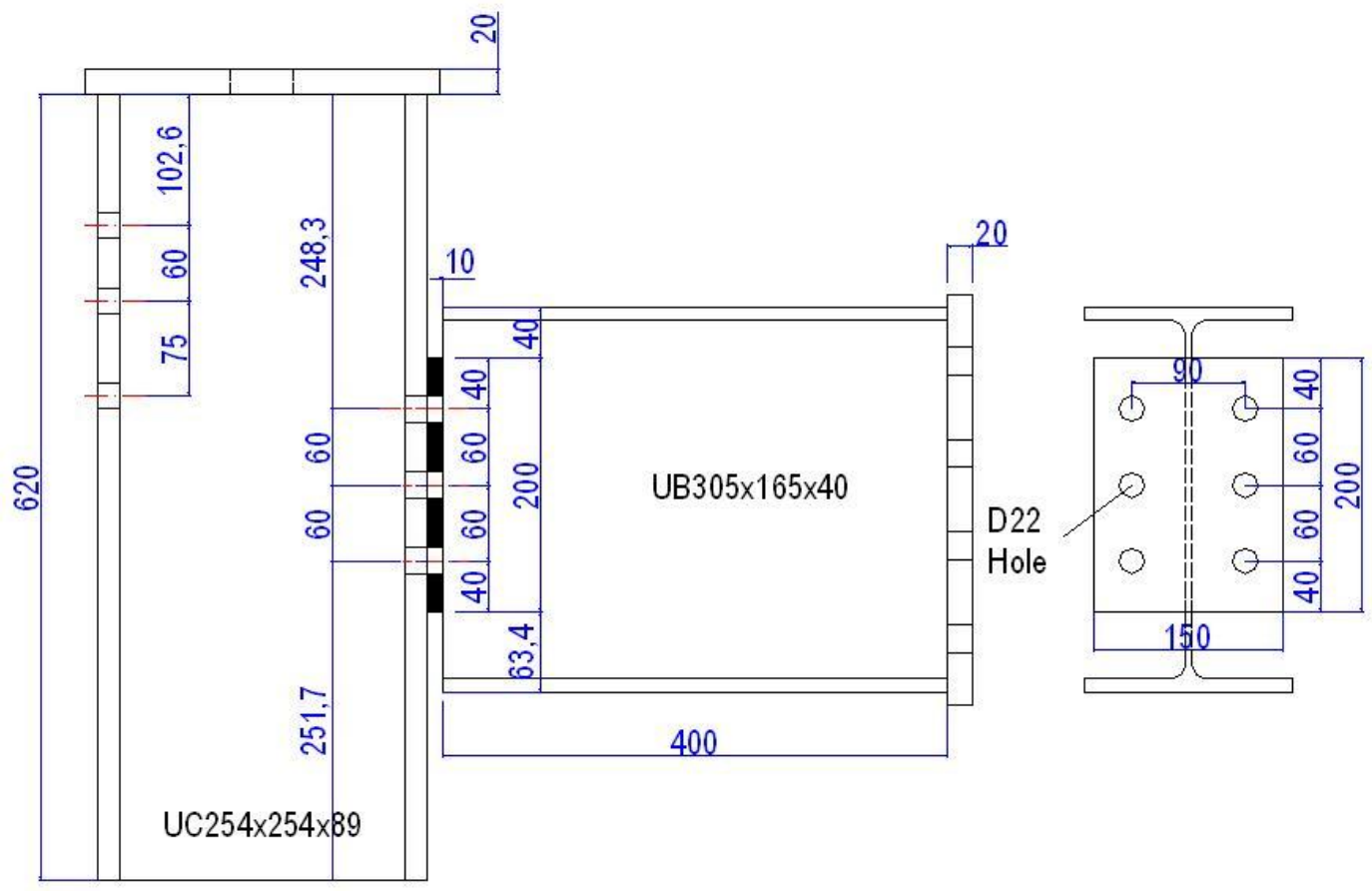

Fig. (8). Geometrical details of the flexible endplate connection (mm). 

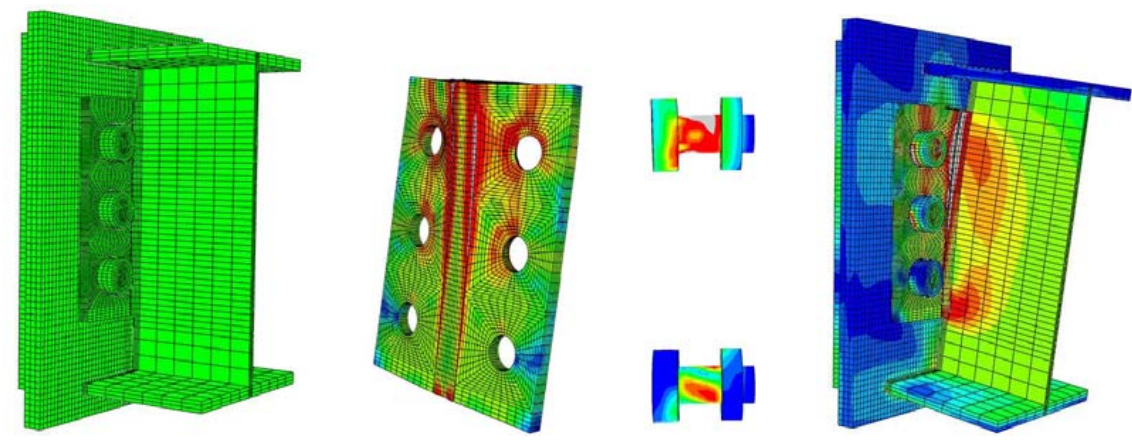

Fig. (9). FE model of flexible end plate connection: deformed and un-deformed shapes.

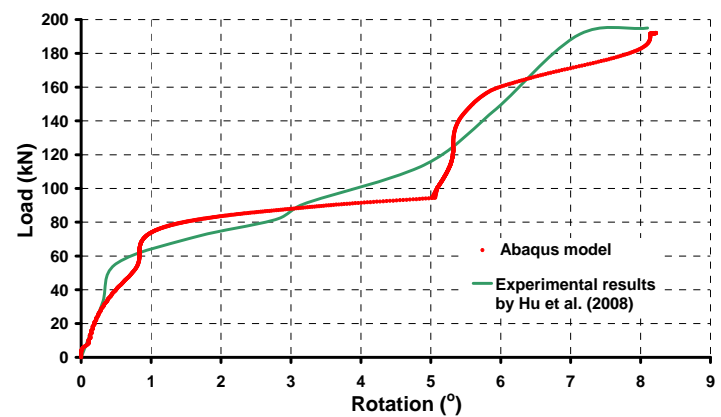

(a) $35^{\circ}$

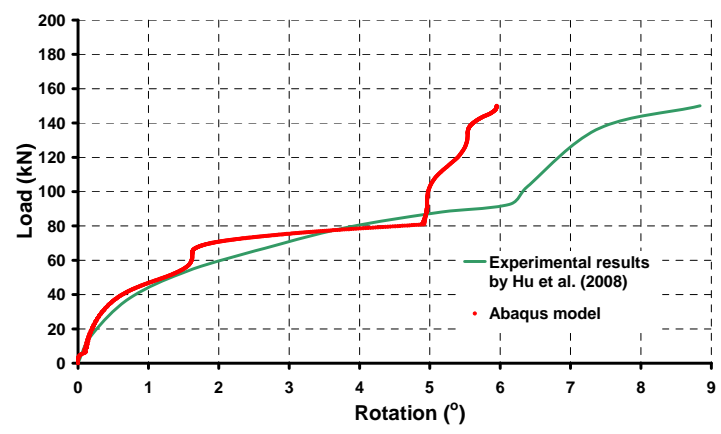

(b) $45^{\circ}$

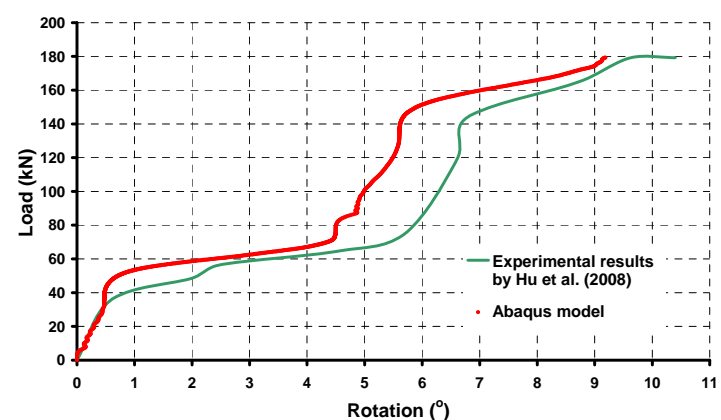

(c) $55^{\circ}$

Fig. (10). Load-Rotation comparisons between FE model and experimental results for flexible end plate connections $\left(35^{\circ}, 45^{\circ}\right.$ and $55^{\circ}$ representing the loading angles of applied forces).

tacted with the column flange. It is apparent in Fig. (10) (a) and (c) that the numerical plots are in good agreement with the experimental plots. Fig. (10) (b) shows some discrepancy between numerical simulation and experimental results, which might be caused by slight variation in geometrical and material properties between structural components such as bolts, welds and endplates in the specimens tested, which is unable to be represented by a unique homogeneous and isotropic finite element model. 

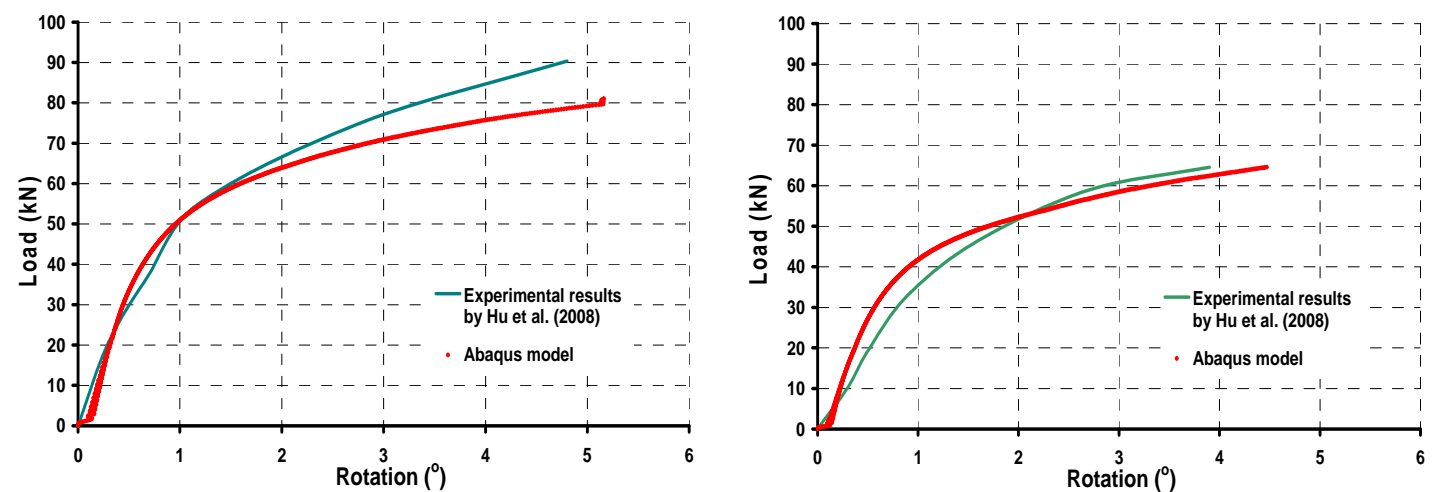

(a) $35^{\circ}-450{ }^{\circ} \mathrm{C}$

(b) $45^{\circ}-450{ }^{\circ} \mathrm{C}$

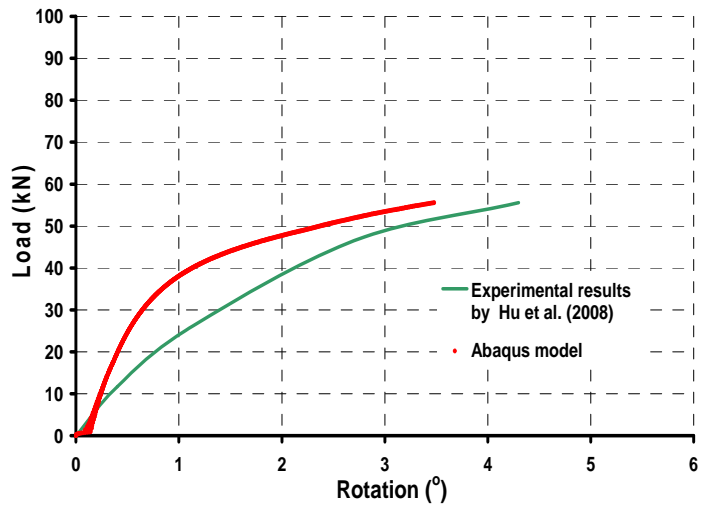

(c) $55^{\circ}-450{ }^{\circ} \mathrm{C}$

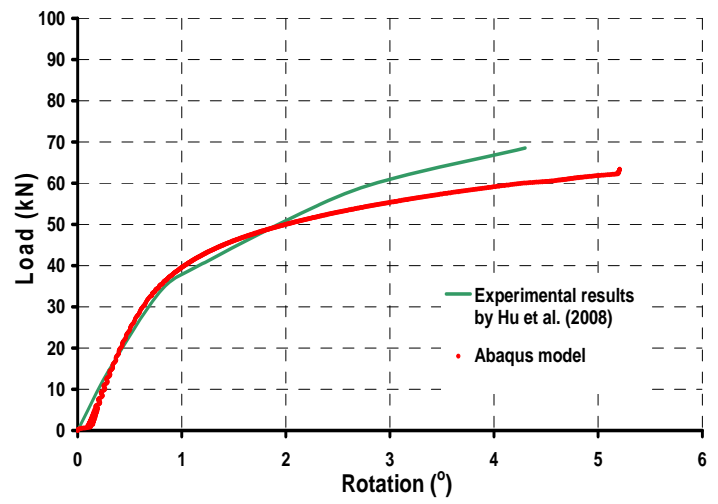

(e) $35^{\circ}-550^{\circ} \mathrm{C}$

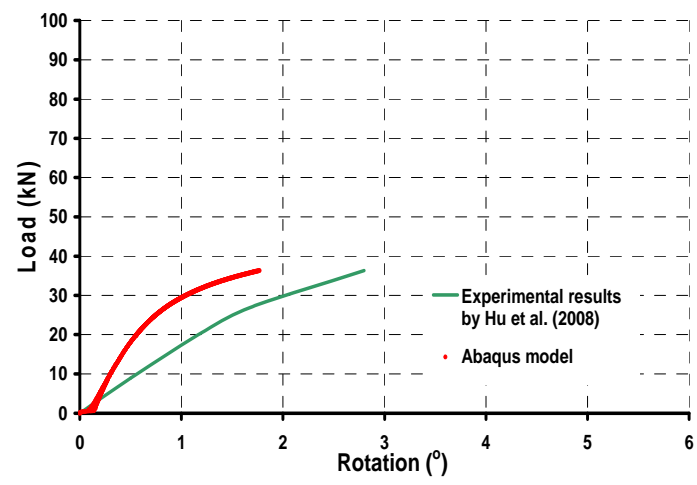

(g) $55^{\circ}-550^{\circ} \mathrm{C}$

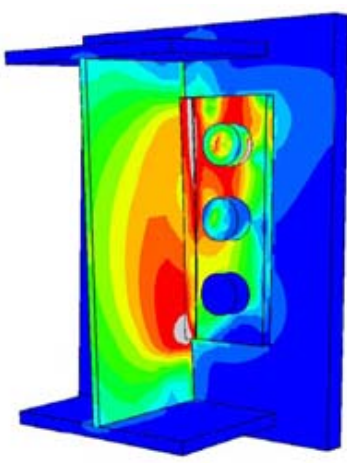

(d) Deformed shape at $450{ }^{\circ} \mathrm{C}$

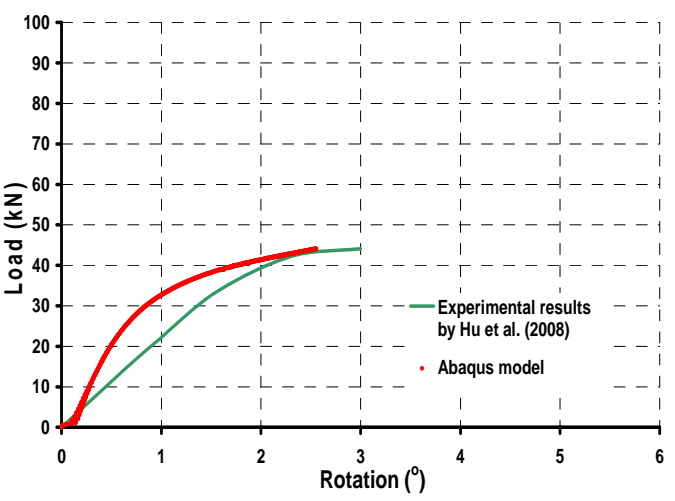

(f) $45^{\circ}-550^{\circ} \mathrm{C}$

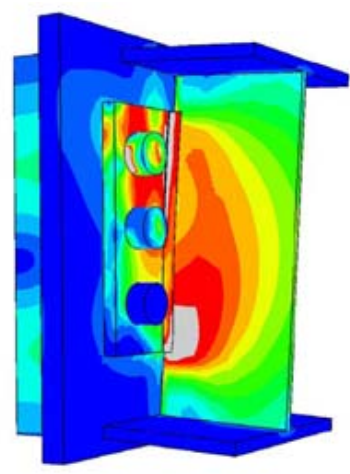

(h) Deformed shape at $550{ }^{\circ} \mathrm{C}$ 
Fig. (11). Contd....

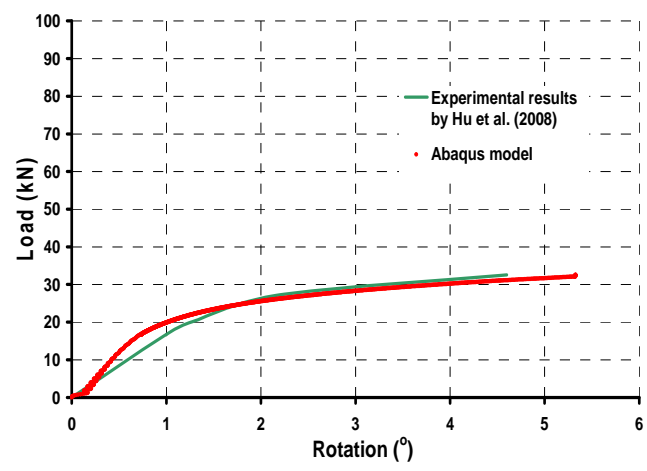

(i) $35^{\circ}-650^{\circ} \mathrm{C}$

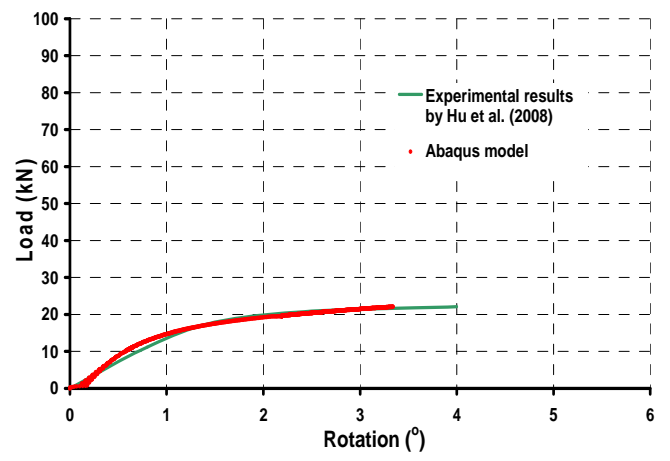

(k) $35^{\circ}-650^{\circ} \mathrm{C}$

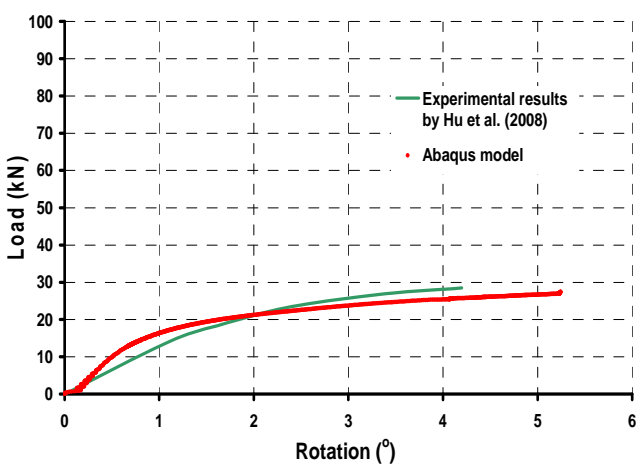

(j) $45^{\circ}-650^{\circ} \mathrm{C}$

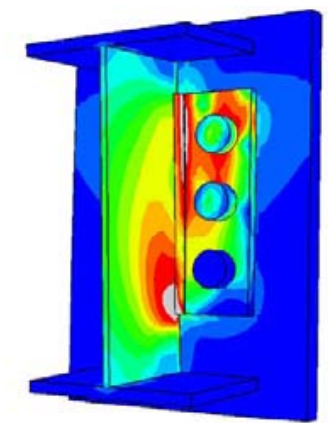

(I) Deformed shape at $650{ }^{\circ} \mathrm{C}$

Fig. (11). Load-Rotation comparisons between FE model and experimental results for flexible end plate connections $\left(35^{\circ}, 45^{\circ}\right.$ and $55^{\circ}$ representing the loading angles of applied forces).

\subsection{Comparison of Flexible End Plate Model at Elevated Temperatures}

Nine experimental tests for flexible end plates have been carried out at temperatures of $450{ }^{\circ} \mathrm{C}, 550{ }^{\circ} \mathrm{C}$ and $650{ }^{\circ} \mathrm{C}$, and the relationships of loads versus rotations are plotted in Fig. (11). A series of finite element simulations have also been conducted and compared with experimental results. The numerical model requires the material properties of steel to be applied at the predetermined temperatures, and the reduction retention factors used are based on recommendations from EC3 [27]. In the finite element modelling, thermal conduction is assumed to have no effect on the connection performance at very high temperatures because of uniform temperature distribution in the specimens. The deformed shapes of connections and finite element models are also shown in Fig. (11) for each temperature.

The experimental and numerical plots demonstrate that the complex finite element models are able to predict the connection behaviour at both ambient and elevated temperatures. It was also observed that the connections, both in the numerical simulations and the experiments, failed by the rupture of endplates before the beam flange contacted with the column flange due to the high stress concentration around the heated affected zone (HAZ). Except for Fig. (11) (g), the curves of loads and rotations, produced by numerical simulation, are in good agreement with recorded experimental data. However, some discrepancies between the numeri- cal analysis and experimental data should be accepted in the finite element simulation, which is because the unique homogeneous and isotropic finite element model are unable to represent the variability in structural components such as material properties and geometrical features, especially under fire conditions.

\section{THE COMPONENT-BASED MODEL (SIMPLIFIED MODELLING)}

The component-based connection model, as explained in the journal publication of $\mathrm{Hu}$ et al. [28], has been used as a simplified approach to represent the connection behaviour. The basic procedure in application of this approach requires the following three steps $[29,30]$ :

i) Identification of the active components in a structural connection. The active components for an endplate connection have contained tension zone components (bolts, welds and T-stubs), compression zone components and vertical shear components (plate bearing component and bolt in single shear). Bolts and welds are classified as brittle elements in a steel connection, and at elevated temperatures, reduction in strength resistance of these components had a side effect on failure mechanisms and ductility of these endplate connections, which has been documented in detail in the journal paper of $\mathrm{Hu}$ et al. [28]. This is an important reason to have them included in this simplified approach to precisely simulate the fire performance of endplate connections. 


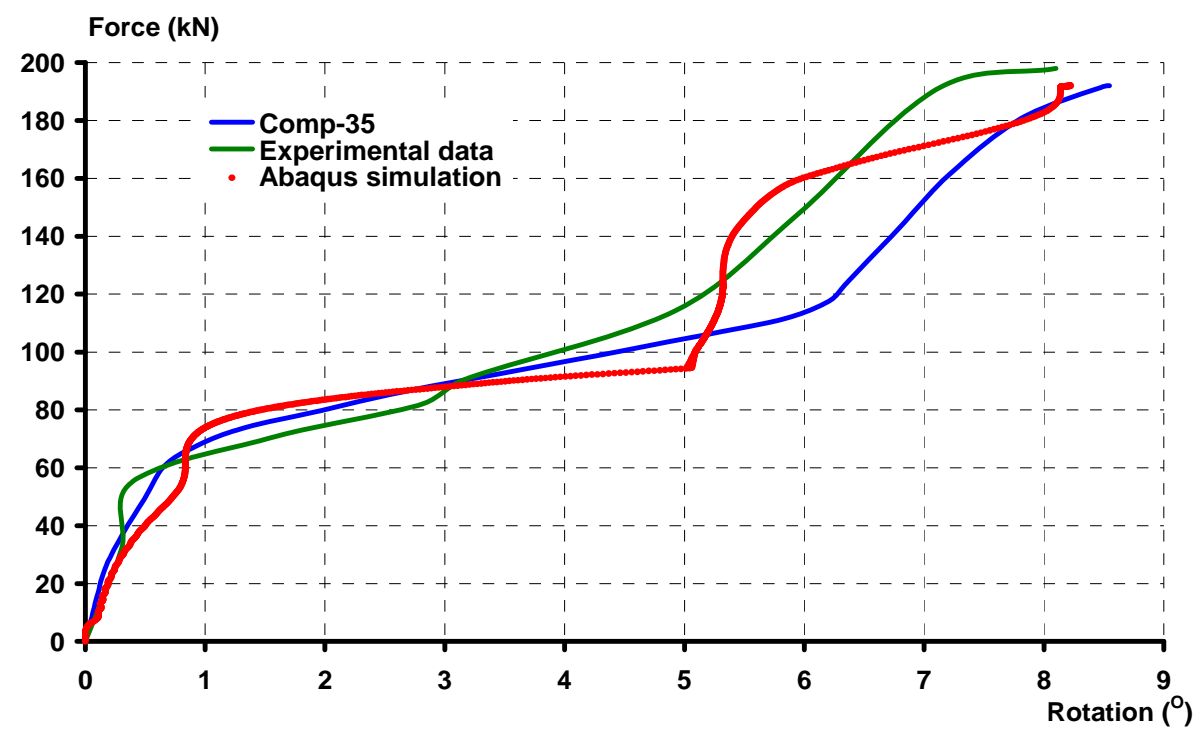

(a) $35^{\circ}$

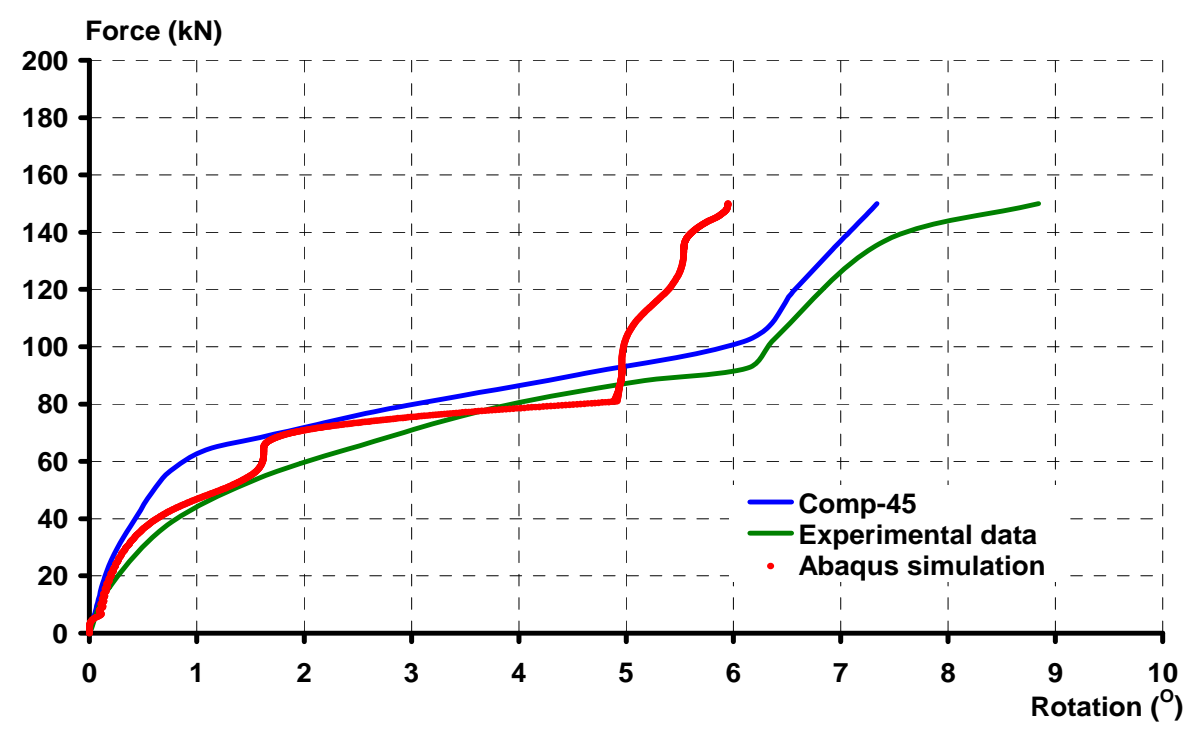

(b) $45^{\circ}$

Force (kN)

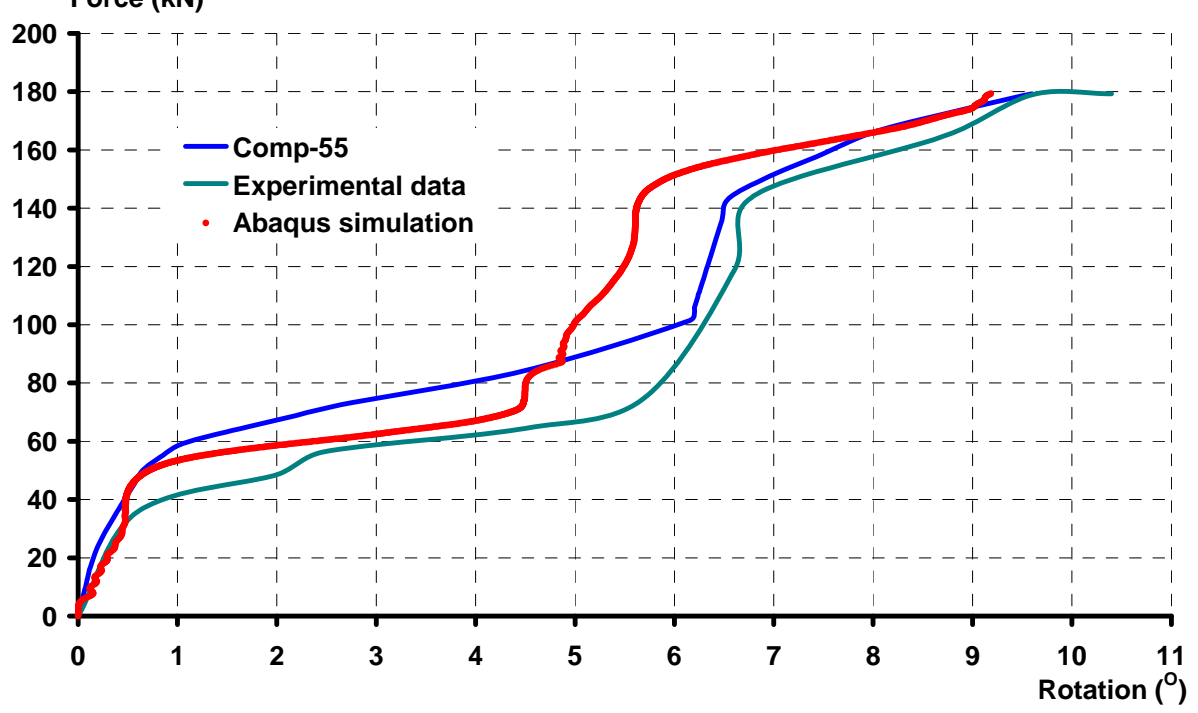

(c) $55^{\circ}$ 
Fig. (12)....

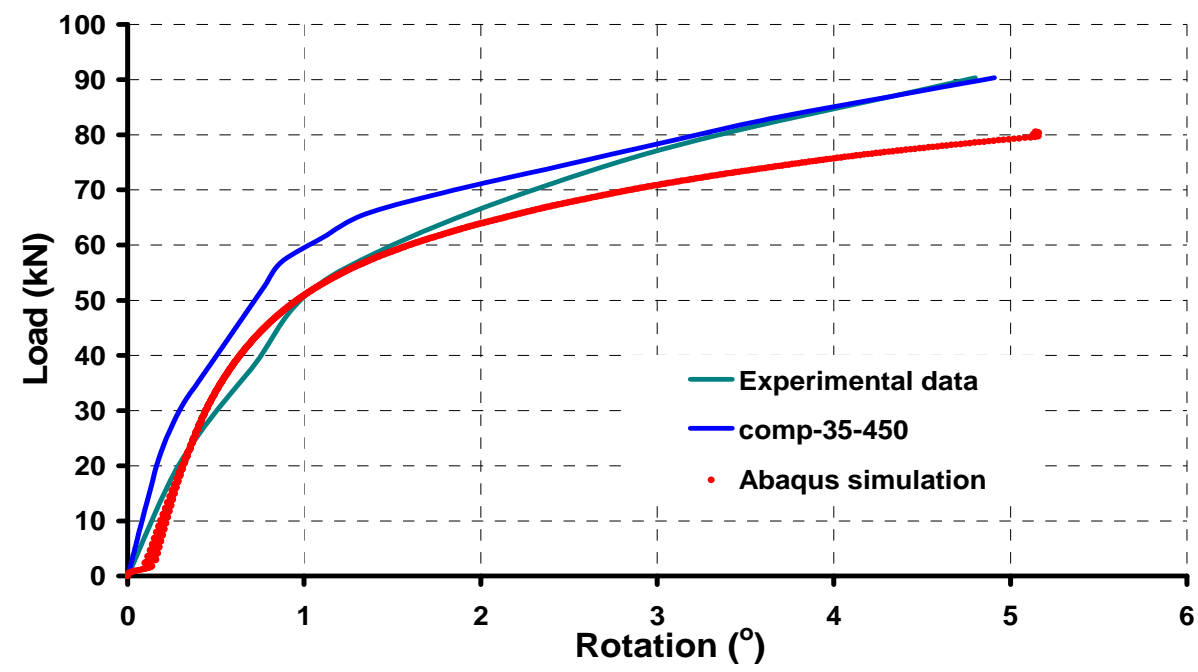

(d) $35^{\circ}-450^{\circ} \mathrm{C}$

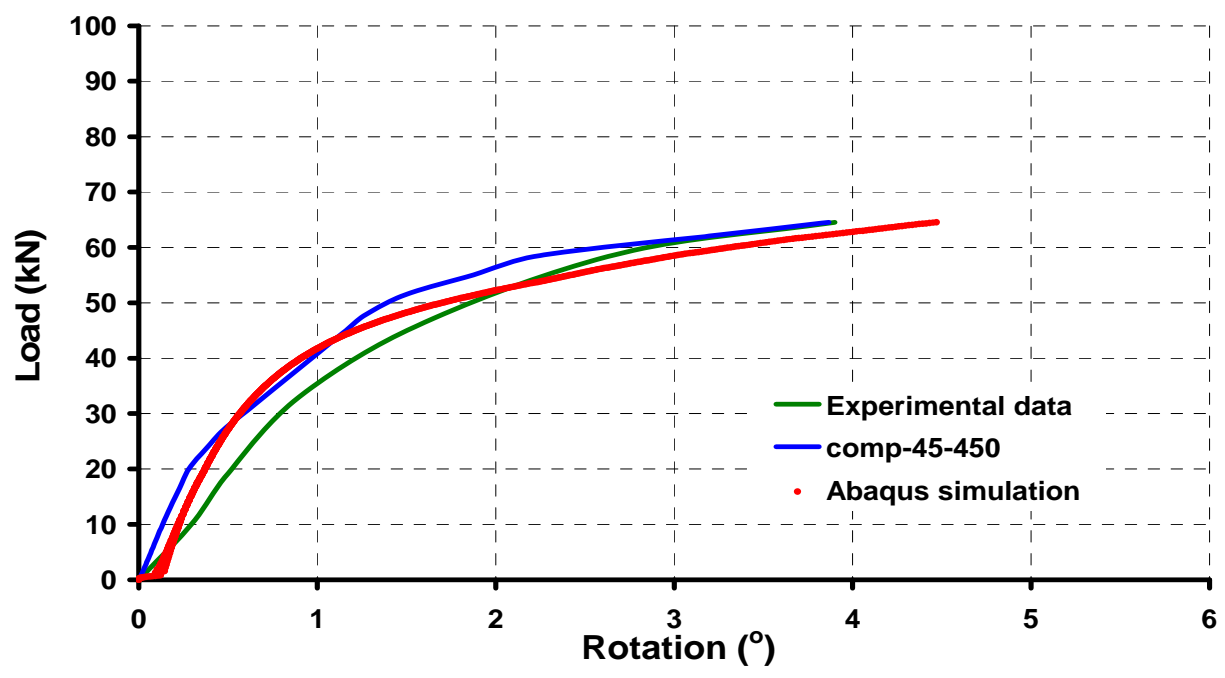

(e) $45^{\circ}-450^{\circ} \mathrm{C}$

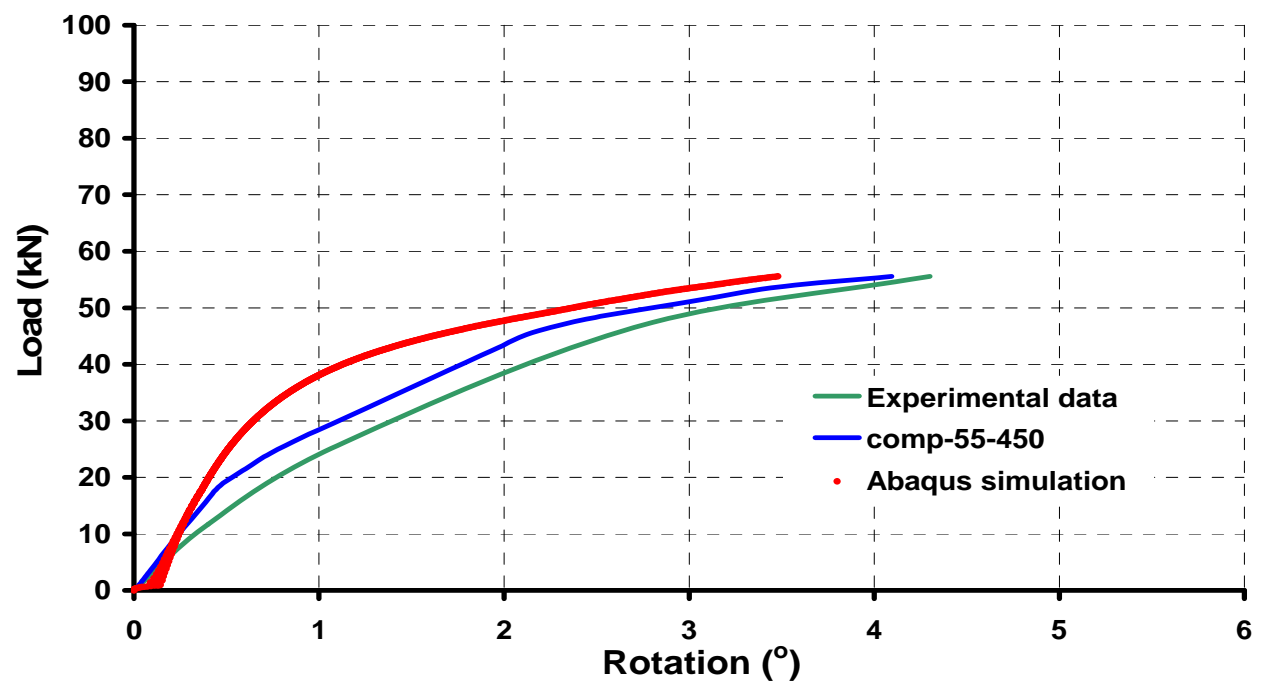

(f) $55^{\circ}-450^{\circ} \mathrm{C}$ 
Fig. (12). Contd....

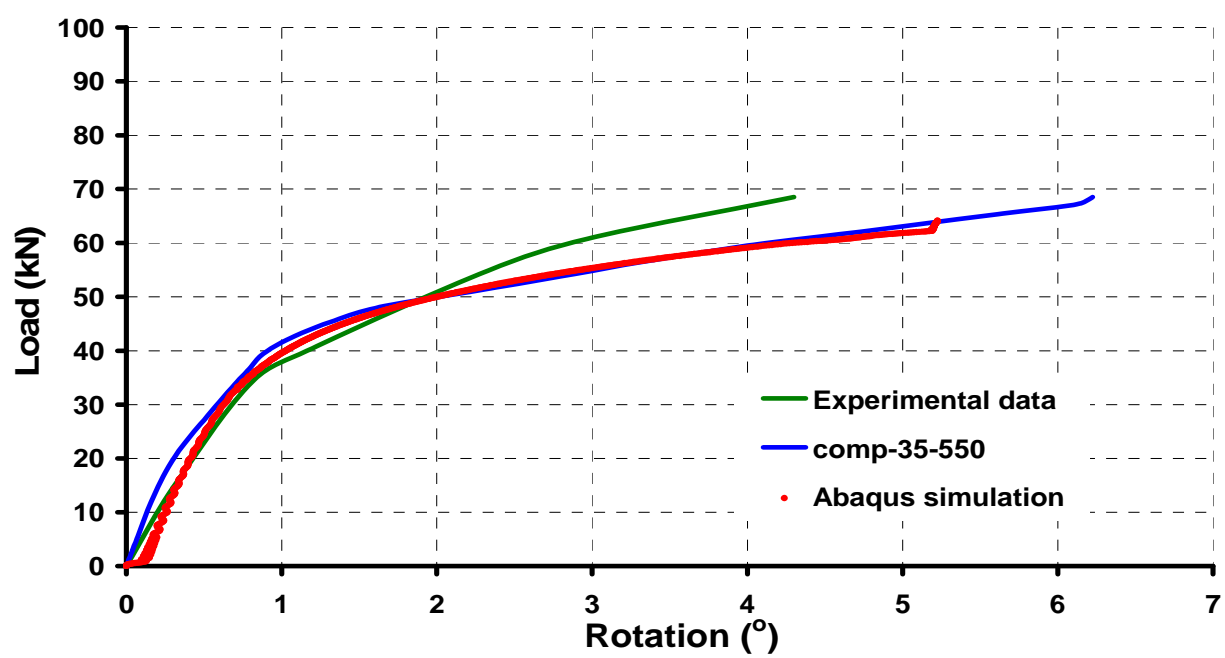

(g) $35^{\circ}-550^{\circ} \mathrm{C}$

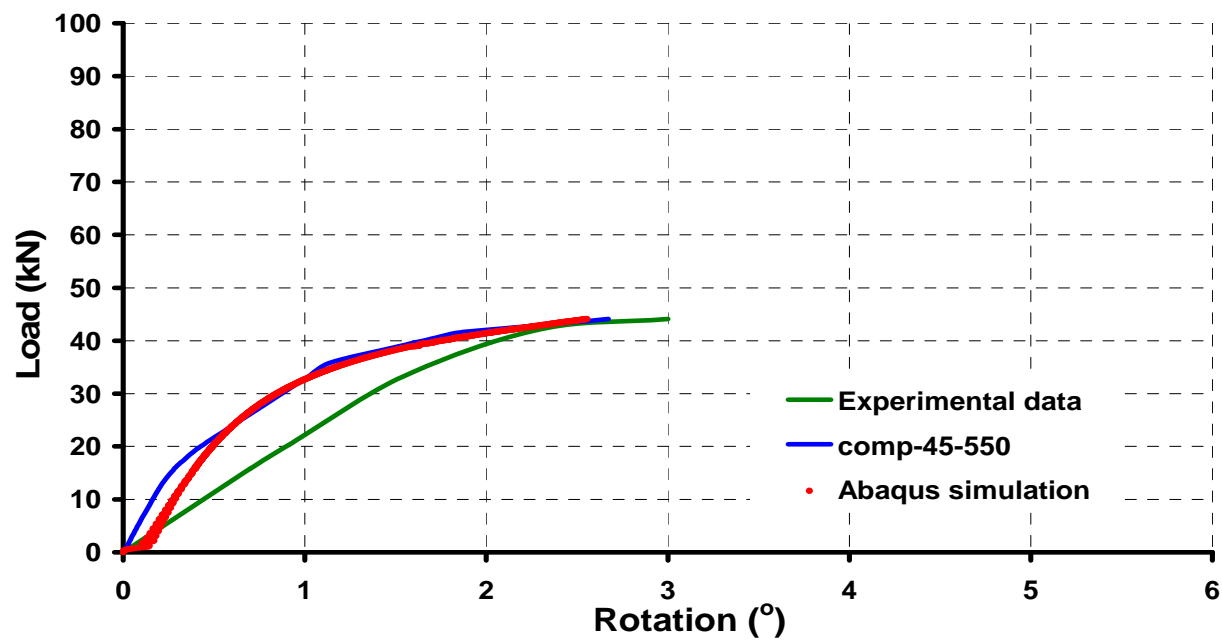

(h) $45^{\circ}-550^{\circ} \mathrm{C}$

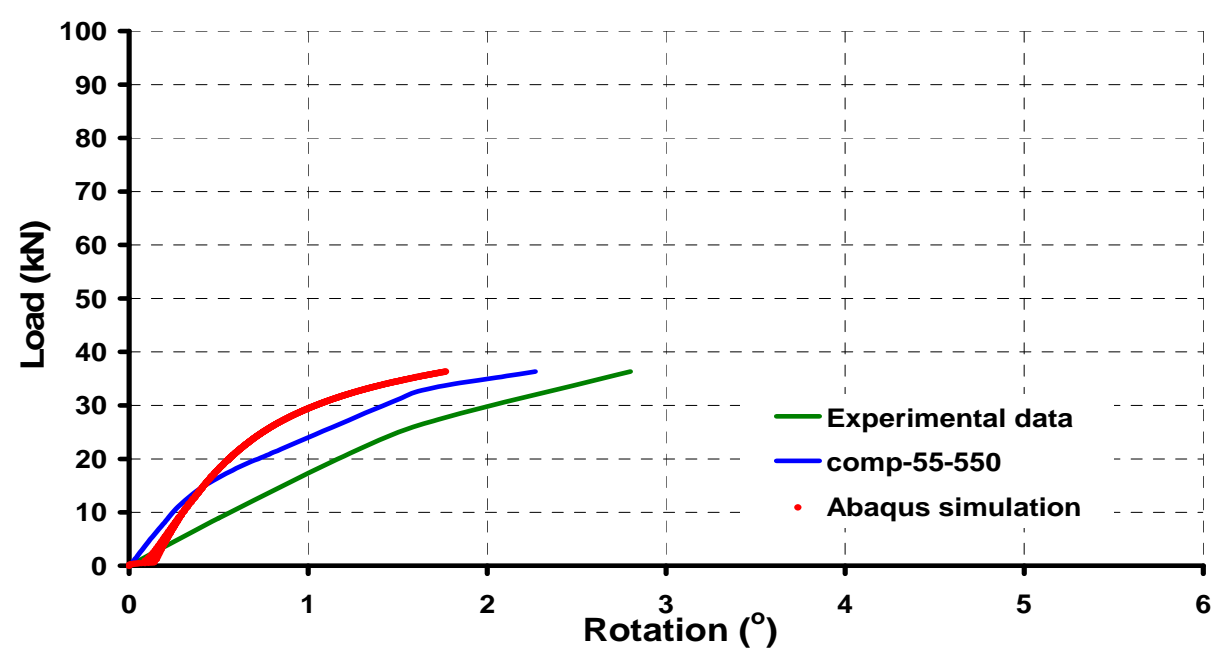

(i) $55^{\circ}-550^{\circ} \mathrm{C}$ 


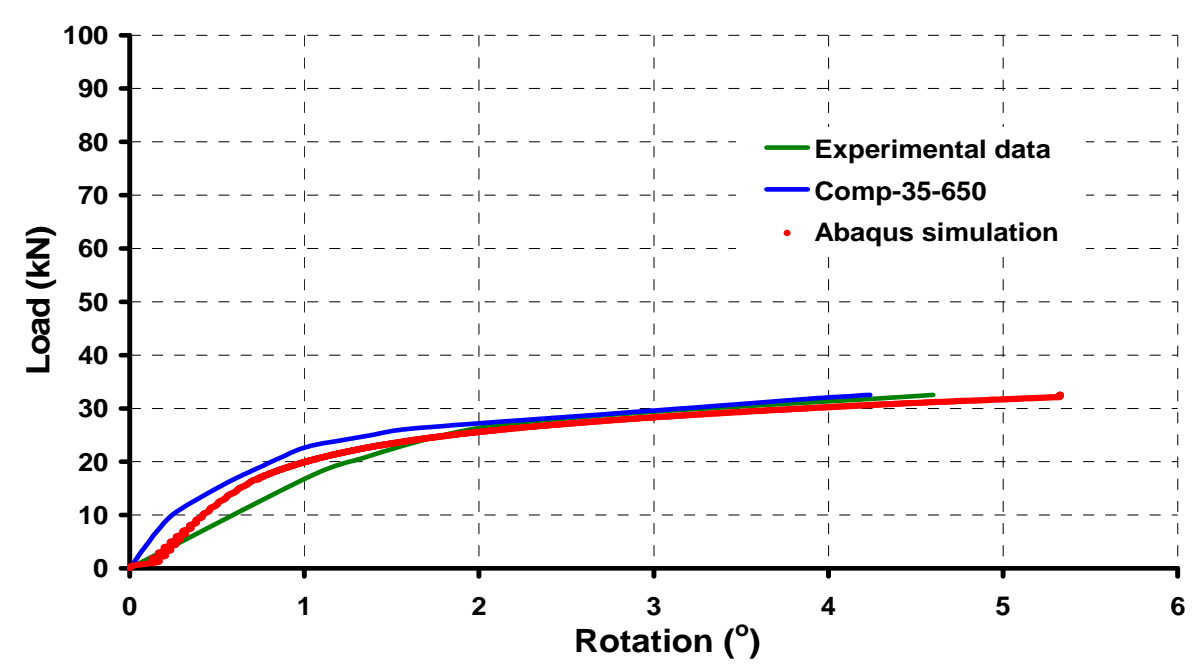

Fig. (12)....

(j) $35^{\circ}-650^{\circ} \mathrm{C}$

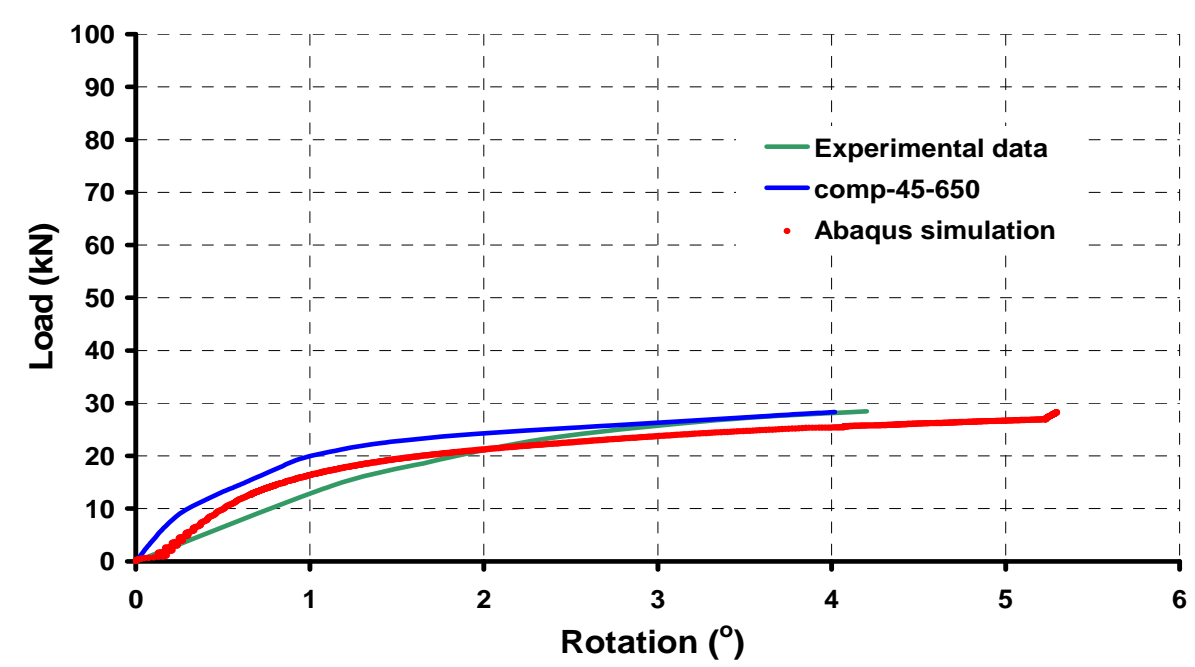

(k) $45^{\circ}-650^{\circ} \mathrm{C}$

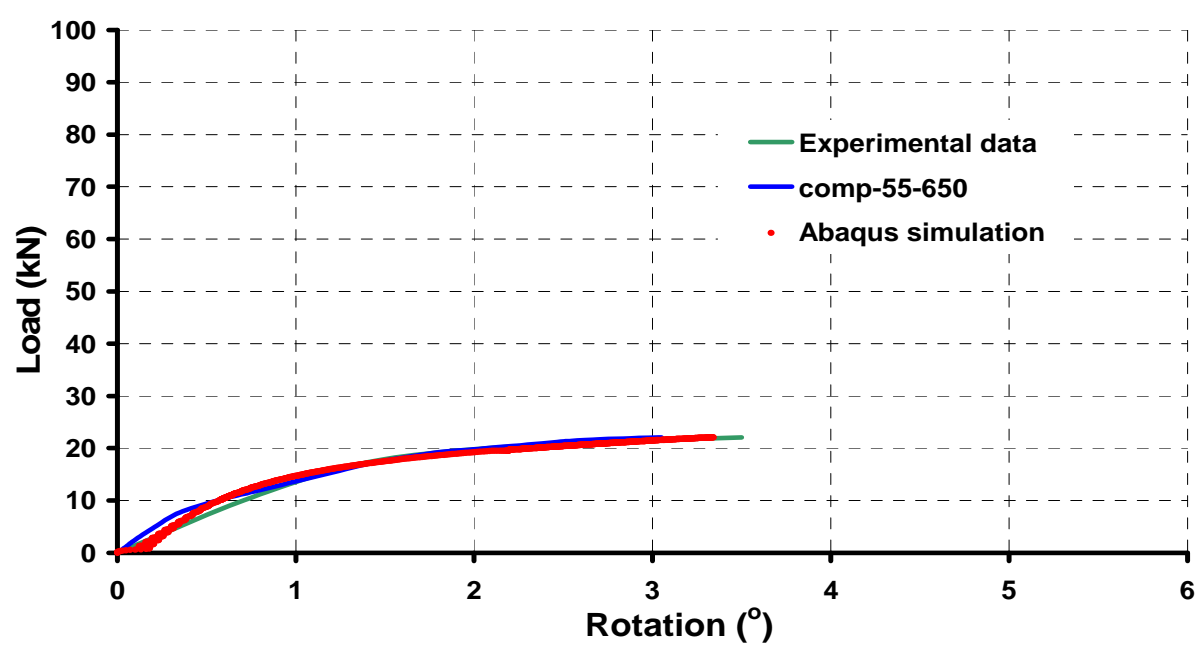

(l) $55^{\circ}-650^{\circ} \mathrm{C}$

Fig. (12). Comparisons between FE models and component-based models for flexible end plate connections $\left(35^{\circ}, 45^{\circ}\right.$ and $55^{\circ}$ representing the loading angles of applied forces). 
ii) Characterization of the nonlinear load-displacement response for each individual component

iii) Assembly of all the components and evaluation of the structural response of the whole joint

In order to provide an accurate and practical prediction for steel connection characteristics, this approach has been extended to include the shear components in the vertical direction instead of assuming infinite vertical stiffness. The second stage behaviour of partial depth endplate connections has been simulated with two spring-like components in the compression zone, which enable this model to capture the connection response after the beam contacts with the column surface. Moreover, the effect of brittle components (welds and bolts) has also been taken into account instead of assuming these components as the strongest in these connections; and the experimental results also proved that these components were vulnerable in fire attacks. In the previous section, the finite element model demonstrated a good agreement with the experimental tests. However, utilization of the finite element model (brick elements) to investigate the connection performance is computationally time-consuming for engineering design. Compared to complex finite element analysis, the analytical component-based model is a more simplified and economical approach for design. It is therefore worth conducting a comparison between the numerical analyses and the analytical component-based models, see Fig. (12).

In the above plots, the green solid curves represent the relationships of loads and rotations reported in the experimental tests and the blue curves are the connection responses predicted by using the analytical component-based approach. The red dotted curves are from the finite element simulations. The above comparisons demonstrate the analytical component-based model to be an accurate and practical prediction method for steel connection characteristics at both ambient and elevated temperatures. In comparison with the complicated finite element simulation, the component-based model is a more simplified and economical approach without significant loss of accuracy, which is able to aid engineers to identify the weakest structural components under fire conditions. Component-based models are an effective solution for the complex connection behaviour prediction in the design of steel or composite-steel frames.

\section{CONCLUSIONS AND RECOMMENDATIONS}

This paper reported the development of finite element models embedded with cohesive elements for prediction of the performance of partial depth endplate connections under fire conditions. Comparisons between the finite element simulation and the component-based modelling were presented, which demonstrated the simplified connection model to be capable of representing the complex behaviour of steel joints. This new simplified method may also be used to analyze the performance of a Rugby-post sub-frame under fire conditions. In the subsequent analyses, steel beams and columns are going to be simulated as finite shell/beam elements and the connection behaviour is to be represented by the simplified models. This sub-frame model will also be used for parametric studies to investigate restrained beam behav- iour under fire attacks with particular emphasis on the role of the connections.

\section{ACKNOWLEDGEMENT}

The research work described in this paper is part of a project funded under Grant EP/C 510984/1 by the Engineering and Physical Sciences Research Council of the United Kingdom. This support is gratefully acknowledged by the authors.

\section{REFERENCES}

[1] Y. C. Wang, Steel and Composite Structures: Behaviour and Design for Fire Safety, Spon Press: London and New York 2002.

[2] D. J. O'Callaghan, and M. A. O'Connor, "Comparison of finite element models of composite steel framed buildings behaviour in fire," In: Proceedings of the First International Workshop on Structures in Fire, Copenhagen: Denmark, 2000.

[3] M. A. O'Connor, and D. M. Martin, "Behaviour of a multi-storey steel framed building subjected to fire attack," Journal of Constructional Steel Research, vol. 46, no. 1/3, p. 295, 1998.

[4] M. Gillie, Development of Generalized Stress Strain Relationships for the Concrete Slab in Shell Models, PIT Project research Report SS1, The University of Edinburgh, 1999.

[5] M. Gillie, A. Usmani M. Rotter and M. O'Connor, Modelling of heated composite floor slabs with reference to the Cardington experiments, Fire Safety Journal, vol. 36, No.8, pp. 745-767, 2001.

[6] M. Sarraj, The Behaviour of Steel Fin Plate Connections in Fire, $\mathrm{PhD}$ thesis, Department of Civil and Structural Engineering, University of Sheffield, UK 2007.

[7] N. Krishnamurthy, and D. E. Graddy, "Correlation between 2- and 3- dimensional finite element analysis of steel bolted end-plate connections", Computers and Structures, vol. 6, pp. 381-389, 1976.

[8] A. R. Kukreti, T. M. Murray, and A. Abolmaali, "End plate connection moment-rotation relationship", Journal of Constructional Steel Research, vol. 8, pp. 137-157, 1987.

[9] G. J. van der Vegte, Y. Makino, and T. Sakimoto, "Numerical research on single-bolted connections using implicit and explicit solution techniques", Memoirs of the Faculty of Engineering, Kumamoto University, Japan, 2002 vol. 47, no.1, pp. 19-44.

[10] A. N. Sherbourne, and M. R. Bahaari, "3D simulation of end-plate bolted connections", Journal of Structural Engineering, vol. 120, no. 11, pp. 3122-3136, 1994.

[11] A. N. Sherbourne, and M. R. Bahaari, "Finite element prediction of end-plate bolted connections behaviour. I: Parametric Study", Journal of Structural Engineering, vol. 123, no. 2, pp. 157-164, 1997.

[12] O. S. Bursi, and J. P. Jaspart, "Benchmarks for finite element modelling of bolted steel connections", Journal of Constructional Steel Research, vol. 43, no. 1-3, pp. 17-42, 1997.

[13] G. J. van der Vegte, "Numerical simulations of bolted connections: the implicit versus the explicit approach", Available at http://www.bouwenmetstaal.nl/ gres_eccs_04/Vegte_Makino_bolted.pdf, 2008.

[14] ABAQUS, Standard user's manual. Hibbitt, Karlsson and Sorensen, Inc, 2006.

[15] N. Gebbeken, H. Rothert, and B. Binder, "On the numerical analysis of end plate connections", Journal of Constructional Steel Research, vol. 30, pp. 177-196, 1994.

[16] O. S. Bursi, and J. P. Jaspart, "Basic issues in the finite element simulation of extended end plate connections", Computers and Structures, vol. 69, pp. 361-382, 1998.

[17] D.P. Flanagan, and T. A. Belytschko, "A uniform strain hexahedron and quadrilateral with orthogonal hourglass control", International Journal for Numerical Methods in Engineering, vol. 17, no.5, pp. 679-706, 1981.

[18] R. Charlier, and A. M. Habraken, "Numerical metallisation of contact phenomena by finite element method", Computers and Geotechnics, vol. 9, pp. 59-72, 1990.

[19] K. J. Bathe, Finite Element Procedures, Prentice Hall: Englewood Cliffs, New Jersey, 1982.

[20] A. M. Kanvinde, I. R. Gomez, M. Roberts, B. V. Fell, and G.Y. Grondin, "Strength and ductility of fillet welds with transverse root 
notch," Journal of Constructional Steel Research, vol.65, pp. 948958, 2009.

[21] Y. Hu, J. B. Davison, I. W. Burgess, and R. J. Plank “Experimental study on flexible end plate connections in fire," In: Proceedings of $5^{\text {th }}$ European Conference on Steel Structures, Graz: Austria, 2008; pp. 1007-1012.

[22] A. Cornec, I. Scheider, and K.H. Schwalbe, "On the practical application of the cohesive model", Engineering Fracture Mechanics, vol. 70, pp.1963-1987, 2003.

[23] I. Scheider, M. Schődel, W. Brocks, and W. Schőnfeld, "Crack propagation analyses with CTOA and cohesive model: Comparison and experimental validation", Engineering Fracture Mechanics, vol. 73, pp. 252-263, 2006.

[24] H. X. Yu, I. W. Burgess, J. B. Davison, and R. J. Plank, "Experimental Investigation of the Behaviour of Fin Plate Connections in Fire," Journal of Constructional Steel Research, vol. 65, pp.723736, 2009a.

[25] H. X. Yu, I. W. Burgess, J. B. Davison, and R. J. Plank, “ Tying capacity of web cleat connections in fire - part 1: test and finite element simulation," Engineering Structures, vol. 31, no.3, pp. 723-736, 2009b.

[26] H. X. Yu, I. W. Burgess, J. B. Davison, and R. J. Plank, "Experimental Investigation of the Behaviour of Flush Endplate Connections in Fire," J Construct Steel Res., vol. 65, pp. 723-736, 2009.

[27] CEN, BS EN 1993-1-8:2005 Eurocode 3: Design of steel structures - Part 1.8: Design of joints, European Committee for Standardisation, Brussels, 2005.

[28] Y. Hu, J. B. Davison, I.W. Burgess, and R. J. Plank, "Component modelling of flexible end-plate connections in fire," International Journal of Steel Structures, vol.9, pp.1-15, 2009.

[29] J. P. Jaspart, Semi-Rigidity in Connections of Structural Steelworks: Theory, Analysis and Design, Lecture notes for Advance Professional Training, Italy, 1999.

[30] K. Weynand, J. P. Jaspart, and M. Steenhuis "The stiffness model of revised annex J of eurocode 3," In: Proceedings of the Third International Workshop: Connections in Steel Structures: Behaviour, Strength and Design, Trento: Italy, 1995; pp. 441-452.

Received: December 07, 2009

Revised: January 20, 2010

Accepted: January 21, 2010

(c) Hu; Licensee Bentham Open.

This is an open access article licensed under the terms of the Creative Commons Attribution Non-Commercial License (http://creativecommons.org/licenses/by-nc/3.0/) which permits unrestricted, non-commercial use, distribution and reproduction in any medium, provided the work is properly cited. 